BEDECARRATZ, Francisco: "Defecto de organización y reglas de comportamiento en la

imputación de las personas jurídicas"

Polit. Crim. Vol. 15, No 30 (Diciembre 2020), Art. 7, pp. 694-728

[http://politcrim.com/wp-content/uploads/2020/12/Vol15N30A7.pdf]

\title{
Defecto de organización y reglas de comportamiento en la imputación de las personas jurídicas*
}

\section{Organisational Fault and Behavioural Rules in the Indicting of Legal Persons}

\author{
Francisco Javier Bedecarratz Scholz \\ Dr. iur. Philipps-Universität Marburg \\ Profesor Facultad de Derecho Universidad Autónoma de Chile, Chile \\ francisco.bedecarratz@uautonoma.cl
}

\section{Resumen}

El presente trabajo realiza un análisis crítico de la concepción tradicional del defecto de organización como requisito de la responsabilidad penal de las personas jurídicas. El autor fundamenta que los deberes de dirección y supervisión consagrados en la ley se concretizan y encuentran su contenido en normas de comportamiento organizacionales de naturaleza extrapenal. Para arribar a esta conclusión, se presenta un análisis doctrinal, del texto legal, de sentencias y de derecho comparado, en orden a fundamentar la naturaleza y el contenido de dichos deberes, proponiendo su categorización y entregando los criterios fundamentales para su futura especificación.

Palabras clave: responsabilidad penal, defecto de organización, compliance, reglas de comportamiento, gobierno corporativo.

\begin{abstract}
This paper provides a critical analysis of the traditional perception of the organisational fault as a rule of attribution in the criminal liability of corporations. In the following pages, the author sustains that the obligations of direction and supervision stipulated in the law are equivalent to organisational rules of behaviour of non-criminal nature. This thesis is based on a doctrinal analysis, on a study of Act No. 20.393, of precedents and of comparative law, that fundament the nature and content of these obligations. Finally, the article proposes a categorization of the obligations and states the fundamental criteria for its future specification.
\end{abstract}

Keywords: criminal liability, organisational fault, compliance, rules of behaviour, corporate governance.

\footnotetext{
* Este artículo ha sido elaborado en el marco del proyecto Fondecyt de Postdoctorado 2019 No 3190874, titulado "Responsabilidad penal de las personas jurídicas y deberes de dirección y supervisión: estudio para dotar de contenido a la conducta típica en instituciones sin fines de lucro", del cual el autor es investigador responsable.
} 


\section{Introducción}

A partir de la segunda mitad del siglo XX, numerosos Estados pertenecientes al mundo occidental incorporaron en sus ordenamientos jurídicos la posibilidad de sancionar penalmente a las asociaciones de personas. ${ }^{1}$ Ello ocurrió en Chile a través de la Ley No 20.393, del 2 de diciembre de 2009, que estableció la responsabilidad penal de las personas jurídicas (en adelante la "LRPPJ"). Dicha ley generó un cambio de paradigma en el Derecho penal vigente en el país, desde la atribución de responsabilidad exclusivamente a personas naturales, hacia el reproche también de organismos colectivos.

La entrada en vigor de la LRPPJ planteó diversos desafíos relacionados con su interpretación y aplicación a casos concretos, propios de toda ley nueva que arriba a un marco legislativo preexistente. ${ }^{2}$ En este orden de cosas, un requisito de imputación que despierta particular interés es el "defecto de organización", concepto que se identifica con una regla de atribución de naturaleza organizacional, sin precedentes en el Derecho penal tradicional. Sin embargo, pese a los numerosos estudios en la materia en los últimos 30 años en Chile y el extranjero, el interés de la doctrina ha sido destinado con mayor énfasis a las reglas de compliance consagradas en la ley y a las técnicas de gestión del riesgo empresarial que lo complementan.

Este enfoque ha ido en desmedro de una interpretación del requisito de imputación a la luz de la dogmática tradicional y de su más amplio contexto normativo-penal. Así, la estructura del defecto de organización y su aplicación práctica poseen en realidad una naturaleza propia, fundada en reglas de comportamiento organizacionales. Se trata de un requisito que permite aplicar el sistema punitivo con categorías casi exclusivamente individuales de imputación, a una realidad colectiva. Frente a una dogmática penal que se ha desarrollado continuamente hace siglos, dicha regla de imputación concebida hace alrededor de 30 años, merece ser estudiada con detención y profundidad, con el fin de permitir un funcionamiento armónico del sistema. El objeto de este trabajo es, precisamente, generar un aporte en ese sentido, desentrañando la estructura del defecto de organización y su naturaleza.

Para cumplir el objetivo anteriormente delineado, en las siguientes líneas se examina la autorregulación como estrategia político-criminal, identificando su fundamento en reglas de comportamiento extrapenales (capítulo $0^{\circ}$ ). Luego, se tematiza el defecto de organización sancionado en el art. $3^{\circ}$ de la LRPPJ y la jurisprudencia reciente sobre la materia (capítulo $0^{\circ}$ ). Posteriormente, el análisis es complementado con un comparado entre las categorías de imputación funcionalmente equivalentes en los ordenamientos español y alemán (capítulo $0^{\circ}$ ). La última parte de este trabajo se dedica a elaborar una propuesta de estructura de los deberes de dirección y supervisión (capítulo $0^{\circ}$ ). Finalmente, los resultados del estudio se consigan en las conclusiones del trabajo.

\footnotetext{
1 Por ejemplo, países en Europa que han introducido modelos sancionatorios contra las personas jurídicas son: Gran Bretaña (1944), los Países Bajos (1951), Portugal (1984), Suecia (1986), Noruega (1991), Islandia (1993), Francia (1994), Finlandia (1995), Dinamarca (1996), Eslovenia (1999), Bélgica (1999), Italia (2001), Grecia (2001), Hungría (2001), Estonia (2001), Malta (2002), Croacia (2003), Suiza (2003), Lituania (2003), Polonia (2003), Austria (2006), España (2010), Liechtenstein (2010) y República Checa (2012).

${ }^{2}$ Algunos de estos desafíos ya habían sido puntualizados, al poco andar de la norma, en HERNÁNDEZ (2012), pp. $75 \mathrm{y}$ ss.
} 


\section{Polit. Crim. Vol. 15, No 30 (Diciembre 2020), Art. 7, pp. 694-728 \\ [http://politcrim.com/wp-content/uploads/2020/12/Vol15N30A7.pdf]}

\section{Autorregulación y deberes extrapenales}

El explosivo aumento en el interés de los Estados nacionales por la responsabilidad penal organizacional es reflejo de una serie de instrumentos internacionales que ordenan la introducción de sanciones efectivas, proporcionadas y disuasivas en contra de las personas jurídicas en los ordenamientos internos. ${ }^{3}$ Estos compromisos internacionales dejan un campo de acción bastante amplio a los legisladores nacionales para modelar, de acuerdo con sus principios de derecho interno y sistemas constitucionales, regímenes sancionatorios contra organizaciones. En este sentido, las legislaciones han tenido libertad para elegir el modelo sancionatorio que mejor se adapte a sus referidos sistemas.

En concordancia con lo anterior, diversas normativas comparadas que consagran la responsabilidad penal de las personas jurídicas contemplan obligaciones de control y vigilancia interna, sistemas de prevención de delitos y estrategias de compliance como normas de imputación, exención o de graduación de la pena. ${ }^{4} \mathrm{Su}$ prevalencia en los modelos de responsabilidad penal de las personas jurídicas ha sido expresión de una estrategia político-criminal preponderante en el concierto comparado, tendiente a la autorregulación de organizaciones. ${ }^{5}$ La forma como los Estados han implementado esta estrategia, se sustenta en los siguientes postulados

\subsection{Autorregulación como estrategia preventiva especial}

El postulado inicial de la estrategia se traduce en que las asociaciones de personas, juntamente con desarrollar sus actividades económicas y sociales, son también fuente de riesgos de naturaleza penal. ${ }^{6}$ Los mismos están dados, por una parte, por la aglutinación de poder o por la actividad económica en particular de asociaciones, que generan un riesgo inmanente por su sola existencia. Por otra parte, se pueden originar por la dinámica del grupo de personas que conforman la asociación, que pueden generar una cultura o un clima organizacional negativo y favorecer la realización de actividades delictivas.

Naturalmente, lo deseable es que estas organizaciones desarrollen sus actividades sin generar daños socialmente relevantes y convivan en armonía con el ordenamiento jurídico. Sin embargo, en consideración a su potencial criminógeno, el Estado se ve en la necesidad de introducir mecanismos para asegurar que las actividades de los entes colectivos no generen

\footnotetext{
${ }^{3}$ En esta categoría de convenios destacan la Convención de la Organización para la Cooperación y el Desarrollo Económico (OCDE) para combatir el cohecho del 17 de diciembre de 1997; el Convenio de las Naciones Unidas para la represión del financiamiento del terrorismo del 9 de diciembre de 1999; la Convención de las Naciones Unidas contra la Delincuencia Transnacional del 15 de noviembre de 2000; y la Convención de las Naciones Unidas contra la Corrupción del 31 de octubre de 2003. En el ámbito europeo es particularmente relevante el $2^{\circ}$ Protocolo del Convenio para la protección de los intereses financieros de las Comunidades Europeas del 19 de julio de 1997. Panorama en BÖSE (2014), pp. 133 y ss.

${ }^{4}$ Por ejemplo, el §8.B.2. de las Federal Sentencing Guidelines de los Estados Unidos; los art. 6 y 7 del Decreto Legislativo $\mathrm{N}^{\circ} 231$ del 8 de junio de 2001 de Italia; y el $\S 7$ in. $2^{\circ}$ de la Bribery Act 2010 del Reino Unido.

${ }^{5}$ NIETO (2008a), p. 81. Ver también NIETO (2008b), pp. 1 y ss.

${ }^{6}$ Riesgos que la mayoría de los autores identifican en el marco de estructuras empresariales más que de asociaciones de personas per se, por ejemplo, ENGELHART (2012), pp. 610 y ss.; NIETO (2008a), pp. 38 y ss.; GARCÍA (2014), pp. 13 y ss.
} 
o, al menos, limiten las consecuencias socialmente lesivas de su actuar. ${ }^{7}$ Estos mecanismos operan a través del incentivo de personas jurídicas a adoptar medidas de organización internas, tendientes a eliminar o disminuir la comisión de delitos por parte de sus dependientes. Así, la autorregulación tiene como objeto desarrollar una cultura de cumplimiento y de conformidad con valores ético-sociales al interior de las organizaciones. ${ }^{8}$

Esta estrategia debe respetar el siguiente principio básico: la regulación es excepcional. ${ }^{9}$ La libertad consustancial que se garantiza a los individuos implica al mismo tiempo, que estos pueden asociarse, fundar personas jurídicas y darles la organización interna y los fines colectivos que estimen convenientes. La intervención estatal que les ordena alterar su estructura interna y cooperar en la detección y sanción de contravenciones, afecta las esferas de protección de cada uno de los derechos esenciales que confluyen en las asociaciones de personas. ${ }^{10}$ Toda intervención en ese sentido debe ser razonable y justificada. ${ }^{11}$

En concordancia con lo anterior, la libertad para organizarse no puede acarrear un abuso ni afectar los derechos y las libertades de terceros. En este sentido, la regulación de organizaciones estará justificada, en la medida que sus estructuras o actividades posean aptitud para lesionar las libertades de otras personas, lo cual se presenta por factores tales como la concentración de poder o la cultura organizacional defectuosa. ${ }^{12}$ Luego, los factores criminógenos o riesgos delictivos especialmente exacerbados de organizaciones, pueden exigir una mayor intervención estatal para resguardar los derechos de terceros. ${ }^{13}$

Por otra parte, la forma ordenada por el Estado para autorregularse no puede ser establecida como la única posible con carácter general para la organización. A mayor abundamiento, no es función propia de un ordenamiento democrático de derecho imponer su visión en cuanto al modo de estructurarse, ni determinar omnicomprensivamente la vida interna de las organizaciones, pues la intervención estatal no debe (ni tampoco puede) derivar en un intervencionismo rector de la conducta social y humana general. Por el contrario, el legislador debe propender a generar los incentivos para adoptar normas de comportamiento acordes con la normativa legal y sectorial, asegurando su efectivo cumplimiento interno. ${ }^{14}$

Con el objeto de promover su efectiva implementación, estas medidas estatales conllevan efectos directos en materia sancionatoria, sea por la vía de la exención, la atenuación o agravación de sanciones corporativas, en caso de que se hubieren cometido uno o más delitos

${ }^{7}$ GARCÍA (2014), p. 14.

${ }^{8}$ LEO-CASTELA et. al. (2019), pp. 406 y ss., idea que también es esencial para una efectiva responsabilidad social corporativa. Desde una perspectiva similar, la autorregulación en el Derecho penal organizacional está orientada al mantenimiento de la vigencia de la norma, lo que se logra concretando "la fidelidad al Derecho por parte de la empresa". GÓMEZ-JARA (2005), p. 270.

${ }^{9}$ ENGELHART (2012), p. 601.

${ }^{10}$ En relación con el ejercicio de garantías que confluyen en asociaciones de personas consúltese RIBERA (2007), pp. 282 y ss. y luego RIBERA (2011), pp. 244 y ss., a propósito de las libertades individuales.

${ }^{11}$ RIBERA (2011), pp. 251 y ss.

${ }^{12}$ ENGELHART (2012), p. 606.

${ }^{13}$ Esto es lo que ocurre, por ejemplo, en materia de lavado de activos, donde debido a la alta probabilidad de actividades delictivas con gran impacto negativo, se establecen deberes de organización y cooperación más extensivos para los sujetos obligados (art. $3^{\circ}$ a $7^{\circ}$ Ley $\mathrm{N}^{\circ}$ 19.913). BEDECARRATZ (2018), pp. 215 y ss.

${ }^{14}$ GARCÍA (2014), pp. 15 y ss. NIETO (2008b), pp. 3 y ss. ENGELHART (2012), pp. 645 y ss. 


\section{Polit. Crim. Vol. 15, No 30 (Diciembre 2020), Art. 7, pp. 694-728 [http://politcrim.com/wp-content/uploads/2020/12/Vol15N30A7.pdf]}

al interior de estas. ${ }^{15}$ De tal modo, las personas jurídicas se ven impulsadas a adoptar modelos de autorregulación, con el fin de mejorar sus expectativas en un proceso penal. Esto es lo que se denomina como "autorregulación regulada". ${ }^{16}$

En concordancia con lo anterior, se ha asumido que los riegos provocados por empresas y otros tipos de organizaciones pueden ser controlados más efectivamente a través de su autorregulación. Argumentos para sostener lo anterior son, por una parte, que las organizaciones poseen un insuperable conocimiento sobre sus fuentes de riesgo y la mejor manera de prevenirlos, en comparación con el Estado. Por otro lado, los fines preventivoespeciales de impedir la comisión de delitos, pueden ser logrados por una organización interna de forma más eficiente y con menor compromiso fiscal. ${ }^{17}$

En consecuencia, los Estados han optado por generar las condiciones necesarias para que los entes colectivos adopten y aseguren el cumplimiento de normas de comportamiento al interior de las organizaciones, prescribiéndoles determinadas formas de organización y de control interno tendientes a disminuir el riesgo de comisión de delitos. De tal manera, la autorregulación regulada constituye una forma de cooperación entre Estados y personas jurídicas en las tareas de prevención de delitos. ${ }^{18}$

\subsection{Defecto de organización como forma de autorregulación}

En el contexto descrito, la responsabilidad penal de las personas jurídicas tiene como presupuesto fundamental el defecto de organización de la entidad. Este concepto se revela como un requisito de imputación y funda la responsabilidad penal en un fallo organizativo de la persona jurídica. Así, la responsabilidad se irroga por un hecho propio de la persona jurídica, consistente en que se ha organizado internamente de modo defectuoso. ${ }^{19}$

El contenido de este defecto de organización fue delineado originalmente por Tiedemann, quien postuló que los delitos o contravenciones cometidas por los órganos de una persona jurídica asumen una categoría organizacional, "dado y en la medida que la asociación -a través de sus órganos o representantes- ha omitido medidas preventivas necesarias para garantizar una operación de negocios ${ }^{20}$ ordenada y no-delictiva." ${ }^{21}$ En caso que se presenten ambos requisitos, es decir el hecho de conexión y la omisión de medidas preventivas, los

\footnotetext{
15 NIETO (2008a), pp. 59 y ss.

${ }^{16}$ Concepto acuñado inicialmente en BRAITHWAITE (1982), pp. 1466 y ss. como "enforced self regulation" y traducible más propiamente como "autorregulación forzada". Sin embargo, en español es más prevalente el término "autorregulación regulada", verbigracia NIETO (2008b), p. 3.

${ }^{17}$ BRAITHWAITE (1982), pp. 1467 y ss. También HERNÁNDEZ (2010), pp. 218 y ss.

18 GARCÍA (2014), p. 16.

${ }^{19}$ FARALDO (2019), p. 53. Ver además FISCAL NACIONAL (2010), p. 7.

${ }^{20}$ Original en alemán "Geschäftsbetrieb”, traducible también como "actividad empresarial”. Sin embargo, aquí se prefiere el término "operación de negocios" para evitar circunscribirnos solamente a empresas.

21 TIEDEMANN (1988), p. 1172. Para este autor, el principio no sería diferente al que fundamenta la punibilidad de personas que cometen delitos en estados de embriaguez absoluta ( $\$ 323$ a del Código Penal alemán, en adelante StGB), la actio libera in causa, o el incumplimiento de deberes de vigilancia ( $\$ 143$ antiguo StGB): no se sanciona por el hecho individual dañino, sino por la previa falta de previsiones destinadas a impedir estos hechos. TIEDEMANN (1988), p. 1173. Ver además DE LA CUESTA (2012), p. 8, en cuanto a su posición como elemento del injusto y no de la culpabilidad de la organización.
} 
delitos individuales se transforman, además, en delitos de la persona jurídica. De tal modo, el defecto de organización se traduce, en buena medida, en la ausencia de un modelo adecuado y eficaz de organización interna, tendiente a la prevención y detección de delitos. ${ }^{22}$

Sin perjuicio de lo anterior, el defecto de organización posee un importante sustrato axiológico, que fundamenta su adopción por sistemas democráticos y/o sociales de Derecho. Así, esta categoría de imputación no es sino la concretización de la responsabilidad social de las personas jurídicas y de la ética organizacional y empresarial. ${ }^{23}$ Más específicamente, el ejercicio de actividades sociales impone, entre otros, un deber de velar porque el mismo no genere efectos sociales negativos tales como un delito, lo cual es consecuencia del clásico sinalagma libertad / responsabilidad. ${ }^{24}$ En este sentido, las organizaciones son parte integrante de la sociedad, con deberes y obligaciones para con el grupo humano, que le imponen un deber de organizarse adecuadamente. ${ }^{25}$

Desde esta perspectiva, el defecto de organización se traduce en normas que imponen una determinada organización interna para las entidades. Sin embargo, para poder cumplir con su cometido ético-social y prevenir más efectivamente la comisión de delitos, el defecto de organización se compone también de normas extrapenales, que especifican la organización de las entidades en distintos ámbitos. Así, en la delimitación de estos deberes y obligaciones cobra especial relevancia la normativa extrapenal, como también las buenas prácticas sectoriales que deben cumplirse por las personas jurídicas en el desarrollo de sus actividades. $^{26}$

Este tipo de normativa se puede insertar como un deber extrapenal para la organización por la vía de una ley penal en blanco, en caso de que tenga su fuente en preceptos regulatorios o infra legales. ${ }^{27} \mathrm{Sin}$ embargo, la conexión entre la categoría de imputación de "defecto de organización" y la normativa extrapenal es más profunda, siendo espejo de aquella existente entre normas de comportamiento y de sanción, la que se explicará sucintamente en el siguiente acápite.

\subsection{Normas de comportamiento y normas de sanción}

Una adecuada comprensión de la categoría de imputación en estudio, requiere una estricta diferenciación teórico-normativa entre normas de comportamiento y normas de sanción. ${ }^{28}$ Recordando la célebre fórmula de Binding, quien comete un delito no infringe la norma penal, pues a través de la concreción del tipo ha actuado en realidad "en conformidad con

\footnotetext{
${ }^{22}$ HERNÁNDEZ (2012), p. 85; NIETO (2008b), p. 14; FARALDO (2019), p. 53, con referencias; GARCÍA (2014), p. 91. Crítica en VAN WEEZEL (2010) p. 122.

${ }^{23}$ NIETO (2008a), p. 51.

${ }^{24}$ HERNÁNDEZ (2010), p. 219 con referencias.

${ }^{25}$ En este contexto, el reproche que se dirige a la persona jurídica se sustenta en el fallo organizativo, que vulnera un deber general de organizarse correctamente. ARTAZA (2013b), p. 547.

${ }^{26}$ ARTAZA (2013b), p. 547.

${ }^{27}$ BEDECARRATZ (2018), pp. 211 y ss.

${ }^{28}$ Sobre la distinción entre normas de comportamiento y normas de sanción RENZIKOWSKY (2005), pp. 115 y ss. También a HRUSCHKA (1994), pp. 343 y ss. Entre nosotros MAÑALICH (2010), pp. 171 y ss.
} 


\section{Polit. Crim. Vol. 15, No 30 (Diciembre 2020), Art. 7, pp. 694-728 [http://politcrim.com/wp-content/uploads/2020/12/Vol15N30A7.pdf]}

ella" ${ }^{29}$ A partir de este razonamiento, se llegó a la conclusión que las normas penales son en realidad normas de sanción, que tienen por función establecer una pena como consecuencia de la infracción a una norma de conducta preexistente. ${ }^{30}$

En concordancia con lo anterior, siendo la pena una consecuencia negativa para un comportamiento no deseado y por lo tanto reprochable, resulta necesario establecer el estándar en virtud del cual ese mismo comportamiento resulta reprobable. ${ }^{31}$ El estándar al que se hace referencia está dado por la norma de comportamiento. Este tipo de normas tienen por naturaleza obligar al sujeto que se encuentra en la situación descrita por el tipo, a realizar u omitir acciones determinadas. ${ }^{32}$

Sin embargo, las normas de comportamiento no son por sí solas capaces de regular confiablemente el comportamiento humano, lo cual sólo puede lograrse mediante el establecimiento de incentivos para su cumplimiento normativo. De ahí que el ordenamiento jurídico establece normas sancionatorias, que disponen consecuencias negativas para aquellos que no cumplen con las exigencias establecidas por las normas de comportamiento. ${ }^{33}$ Luego, la norma de comportamiento constituye el prius lógico o presupuesto valorativo de la norma de sanción. ${ }^{34}$

Existen numerosas concepciones en la teoría normativa que explican la naturaleza de las normas de comportamiento. ${ }^{35}$ Sin embargo, aquí nos interesa resaltar el esquema propuesto por Hruschka, quien les ha adscrito principalmente dos funciones. En la prospectiva, estas son "mandatos o prohibiciones que se dirigen al sujeto sometido a la norma indicándole lo que debe hacer o dejar de hacer; o son reglas permisivas que se dirigen al sujeto sometido a la norma indicándole lo que le está permitido hacer o dejar de hacer". ${ }^{36}$ En consecuencia, este tipo de normas poseen ex ante una función de configuración que influencia y conforma la vida.

Por otra parte, las normas de comportamiento poseen en la retrospectiva o ex post una función de baremo o de medición, que para los tipos delictivos o de justificación llevan aparejada una

\footnotetext{
${ }^{29}$ BINDING (1965), p. 5.

${ }^{30}$ BINDING (1885), p. 155: "Ningún delito del mundo infringe la ley penal según la cual es castigado; todos infringen una norma jurídica fundamentalmente distinta de las leyes penales". En el mismo sentido ZITELMANN (1897), p. 47 (nota al pie $\mathrm{N}^{\circ}$ 7).

${ }^{31}$ MAÑLICH (2010), pp. 171 y ss.

${ }^{32}$ KALIN (2014), p. 50.

${ }^{33}$ KALIN (2014), p. 51.

${ }^{34}$ MAÑALICH (2010), p. 172. Un ejemplo concreto de esta relación es ofrecido por Freund, a propósito del tipo de homicidio imprudente sancionado en el $\S 222$ del StGB: "Como norma de sanción, el $\S 222$ del StGB no regula en absoluto cuándo se presenta una conducta personal negligente, en el sentido del incumplimiento de una norma de comportamiento, destinada a proteger la vida ajena y legitimada en el caso particular por una responsabilidad especial del autor. Por cierto, la ley penal se refiere clara- e inequívocamente a las normas de comportamiento legitimadas extrapenalmente y que reúnen las características necesarias al efecto". FREUND (2015), p. 583, la traducción y el énfasis son nuestros.

35 Para un panorama general sobre la teoría de las normas penales y su relevancia para la reconstrucción del hecho punible, consúltese a VARELA (2016), pp. 68 y ss.

36 HRUSCHKA (1994), p. 344, con ejemplos. Haciendo referencia a las obras de Joachim Georg Daries, Hruschka denomina a este sistema como "lex".
} 
"valoración de la que resulta la antijuricidad o no antijuricidad de la conducta". ${ }^{37}$ Esta valoración puede ser realizada por el juez (el caso más evidente), pero también puede ser el propio sujeto o agente quien valore su propia conducta en su foro interno. Ambas funciones forman un conjunto, de tal modo que toda norma de comportamiento es bifronte: por una parte, configuradora del ser y por otra, valoradora de la acción.

Hruschka distingue además las reglas de imputación, que concibe como separadas de las reglas de comportamiento y forman en sí mismas un sistema propio de reglas. Estas cumplen una función exclusivamente adscriptiva y dirigida, primariamente, a la persona que juzga con posterioridad el hecho. Operan, en consecuencia, en retrospectiva o ex post. ${ }^{38}$

En este sentido, las personas jurídicas son destinatarias de normas de comportamiento, en tanto pueden producir y ser destinatarias de los efectos propios de la norma. ${ }^{39}$ Así, la función del defecto de organización debe erigirse como norma de sanción, que concretiza penalmente la infracción, por parte de la persona jurídica, de normas de comportamiento de naturaleza extrapenal preexistentes. De tal modo, la función del defecto de organización importa, como toda norma de sanción, tipificar la clase o género de infracciones a normas de comportamiento o conducta, establecidas extrapenalmente de forma previa. ${ }^{40}$

\section{El defecto de organización según la Ley $\mathbf{N}^{\circ} \mathbf{2 0 . 3 9 3}$}

La disposición más relevante de la LRPPJ es su art. $3^{\circ}$ in. $1^{\circ}$, que contiene el núcleo fundamental del sistema de imputación penal. ${ }^{41}$ Esta norma dispone que las personas jurídicas pueden ser reputadas penalmente responsables por una serie de delitos individuales, que fueren cometidos directa e inmediatamente en su interés o para su provecho, por sus dueños, controladores, responsables, ejecutivos principales, representantes o quienes realicen actividades de administración y supervisión, siempre que la comisión del delito fuere consecuencia del incumplimiento, por parte de esta, de los deberes de dirección y supervisión (art. $1^{\circ}$ y $3^{\circ}$ de la LRPPJ). ${ }^{42}$

En este sentido, el defecto de organización constituye una categoría propia de imputación en nuestro ordenamiento penal, en virtud de la cual la persona jurídica se transforma en un verdadero garante de vigilancia ${ }^{43}$ en relación con los hechos ejecutados por sus miembros, encontrándose obligada a supervisar a sus agentes.

\footnotetext{
${ }^{37}$ HRUSCHKA (1994), p. 345. acuerdo con el sistema de reglas de comportamiento. HRUSCHKA (1994), p. 346. referencias. FREUND (2019), pp. 8 y ss.

${ }^{41}$ BOFILL (2011), p. 185

${ }^{42}$ HERNÁNDEZ (2010), pp. 220 y ss.

${ }^{43}$ HERNÁNDEZ (2010), p. 225 y, en un sentido similar, COLLADO (2013), p. 166.
}

${ }^{38}$ VARELA (2016), pp. 85 y ss. Además, y según Hruschka, esta operación se da en dos niveles: La imputación de primer nivel (imputatio facti), implica la imputación de un proceso como ejecución de una acción o de una inactividad como omisión de una acción, en la situación concreta según los tipos contenidos en las reglas de comportamiento. Su objeto es determinar si un sujeto es causa moralis de la acción u omisión respectiva. La imputación de segundo nivel (imputatio iuris) representa el juzgamiento del merecimiento de un hecho, de

39 TIEDEMANN (1988), p. 1172. Discusión en GÓMEZ-JARA (2005), pp. 118 y ss., con abundantes

${ }^{40}$ Sobre esta relación entre norma sancionatoria y de conducta, desde la perspectiva de los delitos imprudentes, 
Lo anterior se concretiza a través de varias disposiciones de la LRPPJ: en primer lugar, el art. $3^{\circ}$ in. $1^{\circ}$ in fine exige que la comisión del delito sea consecuencia del incumplimiento, por parte de la persona jurídica, de sus "deberes de dirección y supervisión". A continuación, el in. $3^{\circ}$ de la misma norma establece que los deberes de dirección y supervisión se considerarán cumplidos cuando, con anterioridad a la comisión del delito, la persona jurídica haya implementado un modelo de prevención de delitos conforme a lo establecido en el artículo siguiente. Finalmente, el art. $4^{\circ}$ tipifica la estructura mínima del modelo de organización, administración y supervisión para la prevención de delitos a adoptar por las personas jurídicas.

Este catálogo de disposiciones configura un sistema normativo que exige un análisis escalonado en tres etapas: la primera se enfocará en la estructura típica del modelo de compliance (acápite 2.1.), la segunda en modelos de compliance diseñados al margen de la estructura del art. $4^{\circ}$ de la LRPPJ (acápite 2.2.) y la tercera en los deberes de dirección y supervisión como normas de comportamiento (acápite 2.3.).

\subsection{Modelo típico de compliance, artículo $4^{\circ}$ Ley $\mathbf{N}^{\circ} 20.393$}

El modelo típico de compliance está consagrado en el art. $4^{\circ}$ de la LRPPJ y busca lograr una disminución del riesgo de comisión de hechos punibles a través de medidas de control interno, orientadas a atacar los factores que favorezcan la comisión de los delitos base del art. $1^{\circ}$ de la LRPPJ ${ }^{44}$ Este modelo se compone de las medidas que se exponen sucintamente a continuación.

La primera medida organizativa del modelo se establece en el art. $4^{\circ}$ número 1 de la LRPPJ, que contempla el nombramiento, por parte de la "máxima autoridad administrativa" de la persona jurídica, de un organismo al interior de la empresa denominado "encargado de prevención" y que tiene por función la implementación y supervisión de un sistema de prevención de delitos al interior de la organización, en conjunto con la administración de la persona jurídica ${ }^{45}$ Su duración en el cargo es de tres años, prorrogables por iguales periodos sucesivamente.

Complementando lo anterior, la ley establece que el organismo deberá contar con autonomía respecto de la administración de la organización, sin perjuicio de poder asumir al mismo tiempo funciones de revisión interna o auditoría. Esta característica está destinada a garantizar la independencia del delegado en el ejercicio de sus funciones de control interno y de prevención de delitos, así como evitar conflictos de intereses. ${ }^{46}$ Con todo, en caso de personas jurídicas pequeñas, esto es, cuando sus ingresos anuales no excedan 100.000

\footnotetext{
${ }^{44}$ ROJAS (2019), p. 17.

${ }^{45}$ De acuerdo con el texto vigente de la LRPPJ, el encargado no tendría el rol de garante de vigilancia al interior de la organización, pues ello generaría hipótesis de responsabilidad por omisión de los delitos cometidos en su seno. Sobre la discusión en el contexto español véase, por todos, DÓPICO (2014), pp. 337 y ss.

${ }^{46}$ PIÑA (2012), p. 56.
} 
unidades de fomento, ${ }^{47}$ se faculta que el dueño, socio o accionista controlador asuma personalmente las funciones de oficial de cumplimiento. ${ }^{48}$

El segundo conjunto de medidas organizativas, contempladas en el art. $4^{\circ}$ número 2 de la LRPPJ, radica en el otorgamiento de facultades y medios al encargado de prevención que le permitan ejercer sus funciones. La ley contempla como mínimo, por una parte, el otorgamiento de medios materiales y recursos suficientes para cumplir con su actividad. Cabe destacar, que el cumplimiento de esta obligación es proporcional a las dimensiones y capacidad económica de la persona jurídica. Sin perjuicio de que la ley no establece (ni puede establecer) el quantum de los recursos a asignar, estos deben existir y ser acreditables mediante la asignación en una partida y la ejecución presupuestaria correspondiente. ${ }^{49}$

Por otra parte, en cuanto a los medios del encargado, se establece el acceso directo a la administración para informar de planes y medidas implementadas, así como para rendir cuenta semestralmente, con el fin de garantizar la implementación de medidas preventivas al interior de la organización. Como crítica, si bien la ley cuenta con este deber de información "bottom-up" de los planes de prevención del encargado a la directiva, no establece un deber de información "top-down" de la directiva al encargado sobre decisiones estratégicas y planes de desarrollo de la organización. Ello le permitiría tomar conocimiento de ellas ex ante, influenciarlas para mitigar los riesgos delictivos y cumplir más efectivamente con su función preventiva. ${ }^{50}$

La tercera categoría de medidas se traduce en la creación de un sistema de prevención de delitos por parte del encargado, en conjunto con la administración de la persona jurídica, encaminado a reducir el riesgo de comisión de alguna de las figuras establecidas en el art. $1^{\circ}$ de la LRPPJ. Este es el núcleo esencial del modelo de prevención de delitos. Según el art. $4^{\circ}$ número 3 de la LRPPJ, el sistema consta de cuatro fases: la identificación y prevención de riesgos, junto a la detección y sanción de contravenciones: ${ }^{51}$

a. Se exige en primer lugar, una identificación de las actividades o procesos de la entidad que comporten un riesgo de comisión de actividades delictivas (lit. a). Esto significa debe realizarse un diagnóstico de la exposición de acciones o procesos que efectivamente realiza la organización, al riesgo delictivo de alguna de las figuras contempladas en el art. $1^{\circ}$ de la LRPPJ.

${ }^{47} \mathrm{Al} 1^{\circ}$ julio equivalentes a $\$ 2.869 .546 .000$ CLP o \$3.494.295 USD.

${ }^{48}$ Similar regla existía en Alemania en materia de prevención de activos, que facultaba a directores asumir personalmente las funciones de encargados de prevención, cuando institutos financieros tenían una suma de balance menor a 100 millones de Euros. Sin embargo, esta regulación se restringió considerablemente a partir de la reforma de la Ley de Lavado de Activos alemana (en adelante GwG) implementada en junio de 2017, aceptándose hoy en día solamente la excepción para institutos con menos de 15 trabajadores tiempo completo, con el fin de limitar al máximo los conflictos de intereses. BAFIN (2018), p. 16; ROTH (2019), p. 119.

${ }^{49}$ PIÑA (2012), p. 57.

${ }^{50}$ Ello sí se dispone, por ejemplo, en el $\S 7$ in. $1^{\circ}$ en relación con el $\S 1$ in. 15 de la GwG, respecto a lo cual se ha razonado: "El encargado de prevención de lavado de activos debe situarse a tal nivel en la escala jerárquica de la empresa y estar de tal manera involucrado en las comisiones y comités respectivos, que debe tomar conocimiento de antemano de todas las decisiones estratégicas importantes para, en caso de sospecha de comisión de un delito, poder influenciarlas y mitigar los riesgos delictivos.” ROTH (2019), p. 118.

${ }^{51}$ PIÑA (2012), p. 15. Compárese con las etapas enumeradas en NEIRA (2016), pp. 471 y ss. 


\section{Polit. Crim. Vol. 15, No 30 (Diciembre 2020), Art. 7, pp. 694-728 [http://politcrim.com/wp-content/uploads/2020/12/Vol15N30A7.pdf]}

b. A partir de la identificación de actividades o procesos riesgosos, el sistema de prevención debe regular internamente protocolos, reglas y procedimientos específicos, para prevenir la comisión de delitos en la programación y ejecución de estas mismas tareas (lit. b). Lo anterior debe ir de la mano, además, con la identificación de procedimientos de administración y auditoría, que impida el aprovechamiento de los recursos de la persona jurídica en la comisión de delitos (lit. c).

c. La garantía del cumplimiento del sistema de prevención debe ir naturalmente de la mano de un régimen disciplinario y de sanción interna de contravenciones, así como de procedimientos de denuncia o de persecución de responsabilidades pecuniarias, para el caso de existir efectivamente un incumplimiento del sistema (lit. d).

El modelo típico de compliance contempla, finalmente, mecanismos de aseguramiento de la calidad de los programas implementados. El art. $4^{\circ}$ número 4) lit. a) de la LRPPJ consagra, por una parte, la obligación para el encargado de prevención, en conjunto con la administración de la persona jurídica, de establecer métodos para su aplicación efectiva, su mejora continua mediante la detección y corrección de defectos, así como procesos de actualización. Lo anterior, con el fin de mantener a lo largo del tiempo la vigencia y efectividad del modelo como herramienta de prevención, frente a un generalmente cambiante panorama de riesgos en las actividades de la persona jurídica.

Por otra parte, el art. $4^{\circ}$ número 4) lit. b) de la LRPPJ faculta la certificación de la adopción e implementación del modelo de prevención de delitos (concretamente los ya referidos numerales 1), 2) y 3) del art. $4^{\circ}$ ), a través de organismos externos registrados al efecto en la Comisión para el Mercado Financiero. ${ }^{52}$ En la materia que nos concierne, esta es una forma de acreditar el cumplimiento de los deberes de dirección y supervisión, en tanto la certificación se refiere a una correcta implementación del modelo típico de compliance. ${ }^{53}$ Sin embargo, es necesario destacar que está referida, solamente, a una de entre diversas formas de cumplir los deberes del art. $3^{\circ}$ in. $1^{\circ}$ parte final de la LRPPJ.

Como ya se ha hecho presente en otra oportunidad, ${ }^{54}$ el texto legal no realiza mayor precisión en cuanto al contenido de las obligaciones contempladas en el sistema de prevención de delitos, ofreciendo un marco más bien vago y genérico. ${ }^{55}$ Por ejemplo, el mandato de identificación del riesgo contemplado en el art. $4^{\circ} \mathrm{N}^{\circ} 3^{\circ}$ lit. a) de la LRPPJ no incluye, en estricto rigor, el de estimación de la probabilidad de ocurrencia del riesgo y de su potencial daño en caso de que se materialice. En este ejemplo, resulta discutible que una simple identificación de actividades y procesos riesgosos preste utilidad para su gestión, si no se cuantifica al mismo tiempo el riesgo: no es posible derivar medidas, modificar procesos y

\footnotetext{
${ }^{52}$ Antigua Superintendencia de Bancos e Instituciones Financieras. Este certificado, a su vez, puede presentarse en el marco de un proceso penal, como una forma de acreditar el cumplimiento de sus deberes de dirección y supervisión. Con todo, no es la única manera, pues también puede acreditarse su cumplimiento mediante las reglas generales. BEDECARRATZ (2018), p. 224.

${ }^{53}$ Con todo, esta herramienta no está exenta de críticas, al efecto consúltese a MATUS (2017), pp. 39 y ss.

${ }^{54}$ BEDECARRATZ (2018), pp. 213 y ss.

${ }^{55}$ ARTAZA (2013b), p. 568; PIÑA (2012), p. 16.
} 
priorizar recursos para la aminoración del riesgo, si se desconoce su impacto y probabilidad de ocurrencia. ${ }^{56}$

La ley guarda silencio sobre este y otros aspectos cruciales de los sistemas de prevención de delitos, lo cual implica que los requisitos generales que establece no son de ninguna manera autosuficientes. ${ }^{57}$ Por lo tanto, deben ser complementados por otros criterios y principios fijados por vía extrapenal, así como buenas prácticas asentadas en el sector de actividades en que se desempeña la persona jurídica. ${ }^{58}$

En la jurisprudencia reciente de los tribunales de justicia chilenos, ${ }^{59}$ el requisito de defecto de organización se da por acreditado al constatar la ausencia del modelo típico de compliance antes enunciado. Por ejemplo, en la sentencia pronunciada en el caso Universidad del Mar, ${ }^{60}$ se exhibe una fundamentación relativamente detallada sobre el incumplimiento de los deberes de dirección y supervisión. En específico, luego de establecer que las personas jurídicas imputadas no adoptaron ningún modelo de prevención de delitos, la sentencia constata desagregadamente el incumplimiento de todos los requisitos establecidos en el art. $4^{\circ}$ de la LRPPJ, incluidos los específicos del sistema de prevención de delitos del número $3 .{ }^{61}$

Sin embargo, en la misma sentencia está completamente ausente la consideración del tribunal acerca de la inexistencia de otro tipo de medidas alternativas de prevención de delitos, o del incumplimiento de normas de comportamiento que equivalgan a los deberes de dirección y supervisión del art. $3^{\circ}$ in. $1^{\circ}$ parte final de la LRPPJ. Así, el juzgador asumió que la falta de implementación del modelo de prevención de delitos del art. $4^{\circ}$ de la LRPPJ acarrea necesariamente el incumplimiento de los deberes de dirección y supervisión. Este razonamiento es incompleto, como se verá.

\subsection{Modelos atípicos de compliance}

Como ya se ha puntualizado, los programas de prevención de delitos son una expresión de la estrategia estatal de autorregulación regulada, cuyo principal objetivo es impedir o, al menos, permitir esclarecer de mejor forma la comisión de hechos punibles perpetrados al interior de organizaciones. ${ }^{62}$ Al tipificar un modelo de prevención de delitos, el legislador chileno ha especificado la forma de organización interna a ser adoptada por las personas jurídicas, con el fin de controlar los riesgos penales generados por su propia actividad. ${ }^{63}$ Sin embargo, se

\footnotetext{
${ }^{56}$ Metodologías para el análisis del riesgo en ALBERTZ (2019), pp. 141 y ss., como también en PIÑA (2012), pp. 40 y ss.

${ }^{57}$ PIÑA (2012), pp. 9 y ss.

${ }^{58}$ Normativa extrapenal cuya relevancia ya ha sido destacada en ARTAZA (2013a), pp. 346 y ss., y condensada en ARTAZA (2019), pp. 46 y ss.

${ }^{59}$ Una relación en BALMACEDA et al. (2019), pp. 233 y ss. respectivamente. Ver además a NAVAS y JAAR (2018), pp. 1032, especialmente en lo referente a la aplicación de los demás presupuestos de imputación del art. $3^{\circ}$ de la LRPPJ.

${ }^{60}$ Sentencia pronunciada por el $8^{\circ}$ Juzgado de Garantía de Santiago, causa RIT N $^{\circ} 4799-2012$, RUC N ${ }^{\circ}$ 1200084351-0, del 2 de junio de 2016 (caso Universidad del Mar).

${ }^{61}$ Caso "Universidad del Mar", considerando primero in fine.

62 BEDECARRATZ (2018), p. 209.

${ }^{63}$ BOFILL (2011), pp. 189 y ss.
} 


\section{Polit. Crim. Vol. 15, No 30 (Diciembre 2020), Art. 7, pp. 694-728 [http://politcrim.com/wp-content/uploads/2020/12/Vol15N30A7.pdf]}

suscita la cuestión respecto a si las organizaciones pueden adoptar otros modelos de prevención de delitos, destinados a reducir los riesgos penales originados por una organización.

Esta pregunta ha sido respondida por parte de la doctrina nacional con una afirmativa categórica. ${ }^{64}$ Semánticamente, la propia ley deja como facultativa la implementación del modelo de prevención que contempla, al disponer que las personas jurídicas "podrán adoptar el modelo de prevención" establecido normativamente. Es esta la expresión que abre la puerta a que existan otras formas de cumplir con los deberes de dirección y supervisión de la persona jurídica. En efecto, es perfectamente posible que la persona jurídica adopte otro tipo de medidas que cumplan con deberes de dirección y establezca otra forma adecuada de supervisión de sus directivos y empleados subalternos, lo cual deberá ser considerado como cumplimiento de sus deberes. ${ }^{65}$ De ahí que el art. $4^{\circ}$ de la LRPPJ, por obra y gracia de su propia redacción, tiene un "indudable carácter potestativo". 66

En caso de que se adopte un modelo de prevención de delitos atípico, entonces las medidas de control implementadas deben ser al menos igualmente idóneas a las enumeradas en el art. $4^{\circ}$ de la LRPPJ. En tal evento, no se verificaría la presunción simplemente legal del art. $3^{\circ}$ in. $3^{\circ}$ de la LRPPJ, en orden a que la persona jurídica ha cumplido con sus deberes de dirección y supervisión, pues esta opera solamente con la adopción de un modelo con las características típicas. Sin embargo, se podría lograr de todos modos la exención de la persona jurídica, acreditando la implementación de medidas idóneas para prevenir delitos como el cometido en la especie y, en consecuencia, el cumplimiento de los deberes dirección y supervisión del art. $3^{\circ}$ in. $1^{\circ}$, parte final de la LRPPJ.

En la sentencia pronunciada en el caso Constructora Pehuenche,${ }^{67}$ es posible observar otra técnica jurisdiccional. Concretamente, el tribunal dio por acreditado el incumplimiento de los deberes de dirección y supervisión de la persona jurídica, sobre la base de que la sociedad "no adoptó ni implementó, con anterioridad a los hechos, un modelo de prevención de delitos en los términos del art. $4^{\circ}$ de la misma ley, ni contó con mecanismos para prevenir la conducta de soborno antes descrita. ${ }^{, 68}$. En este sentido, existe un cierto reconocimiento a la posibilidad de otros mecanismos para prevenir la conducta de soborno por la cual se persigue a la persona jurídica. Sin embargo, el fallo se limita a realizar una mera constatación fáctica, sin elaborar estos otros mecanismos ni menos fundamentar la conclusión alcanzada.

\footnotetext{
${ }^{64}$ HERNÁNDEZ (2010), pp. 225 y ss. VAN WEEZEL (2011), pp. 138 y ss. PIÑA (2012), p. 8. NAVAS y JAAR (2018), pp. 1038 y ss.

${ }^{65}$ BEDECARRATZ (2018), p. 214.

${ }^{66}$ GARCÍA (2012), p.70. Sin embargo, este no habría sido el propósito original de la norma, como bien detalla HERNÁNDEZ (2010), p. 226, nota al pie $\mathrm{N}^{\circ} 88$.

${ }^{67}$ Sentencia pronunciada por el $7^{\circ}$ Juzgado de Garantía de Santiago, RIT No $11862-2014$, RUC N $^{\circ} 1400129785-$ 7, del 19 de agosto de 2015 (caso Constructora Pehuenche).

${ }^{68}$ Considerando primero, el énfasis es nuestro. En el considerando octavo, el tribunal da por no controvertido este hecho y, por lo tanto, como acreditado conforme al art. 413 lit. c) del Código Procesal Penal, en relación con el art. 406 in. $2^{\circ}$ del mismo cuerpo legal.
} 
Por su parte, en la sentencia pronunciada en el caso Salmones Colbún, ${ }^{69}$ el tribunal razonó de una manera similar: "La comisión de los referidos hechos ilícitos fue consecuencia del incumplimiento, por parte de las empresas imputadas, de sus deberes de dirección y supervisión, con arreglo a lo dispuesto en la Ley $\mathrm{N}^{\circ} 20.393$, por cuanto no adoptaron ningún tipo de medida idónea de prevención de delitos a su interior ni tampoco implementó un modelo de prevención de delitos en los términos del art. $4^{\circ}$ del referido cuerpo legal, sin dar cumplimiento de forma alguna a los referidos deberes". ${ }^{70}$

La redacción del considerando citado es alternativa, al hacer referencia a "ningún tipo de medida idónea de prevención de delitos" por una parte, y al modelo consagrado en el art. $4^{\circ}$ de la LRPPJ por otra. Existe, consecuentemente, un reconocimiento a distintas formas de cumplir con el requisito de deberes de dirección y supervisión; pero de igual forma que en la sentencia dictada en el caso Constructora Pehuenche, el tribunal es poco claro en la diferenciación y silente en cuanto a su fundamentación.

\subsection{Deberes de dirección y supervisión como reglas de comportamiento}

Cabe plantearse ahora, si es posible cumplir con los deberes de dirección y supervisión que sanciona el art. $3^{\circ}$ in. $1^{\circ}$ de la LRPPJ, a través del cumplimiento de normas de comportamiento extrapenales que no se presenten como un "modelo de prevención de delitos". En otras palabras, analizar si las personas jurídicas, apartándose de paradigmas orientados exclusivamente a la prevención del riesgo, pueden satisfacer los deberes de dirección y supervisión también a través de una estructura interna, cultura organizacional y forma de operar sus negocios, que cumpla con normas de comportamiento previas a la norma de imputación penal.

Para responder esta pregunta, es necesario volver a un principio fundamental de la "autorregulación regulada": los modelos típicos para controlar el riesgo no pueden ser la única forma de cumplir con el mandato legal de prevención de delitos. ${ }^{71}$ De lo contrario, deja de ser autorregulación y pasa a ser directamente una regulación, es decir, una imposición de la autoridad sin posibilidad de cumplimiento alternativo. Lo anterior se puede entender más claramente a la luz de un principio anglosajón vigente en materia de gobiernos corporativos: "comply or explain". ${ }^{72}$ Los privados pueden cumplir o no con la normativa de compliance, pero si optan por no hacerlo, deben tener la oportunidad de explicar que sí está cumpliendo con los principios y la finalidad que informan la norma, solamente que de manera distinta.

\footnotetext{
${ }^{69}$ Sentencia pronunciada por el Juzgado de Garantía de Talca, causa RIT No 9211-2012, RUC No 1201092968 5, del 12 de agosto de 2013 (caso Salmones Colbún).

${ }^{70}$ Considerando cuarto, el énfasis es nuestro. En el considerando sexto, la sentencia hace referencia solamente al modelo del art. $4^{\circ}$ de la LRPPJ.

${ }^{71}$ En contra GARCÍA (2012), p. 70.

${ }^{72}$ El principio tuvo su origen en el Cadbury Code de 1992, cuerpo que se transformó posteriormente en el Código de Gobierno Corporativo del Reino Unido, manteniéndose con adaptaciones vigente hasta la actualidad. Ha sido incorporado en las leyes sobre gobierno corporativo de, entre otros, Alemania (Deutscher Corporate Gobernance Kodex) y los Países Bajos (Nederlandse corporate governance code). Este principio ha sido adoptado en Chile por la Norma de Carácter General N ${ }^{\circ} 341$ del 29 de noviembre de 2012, de la Superintendencia de Valores y Seguros, hoy Comisión para el Mercado Financiero.
} 


\section{Polit. Crim. Vol. 15, No 30 (Diciembre 2020), Art. 7, pp. 694-728 [http://politcrim.com/wp-content/uploads/2020/12/Vol15N30A7.pdf]}

Volviendo a la norma que concretiza el defecto de organización, se debe dejar al juez la decisión respecto a si los estándares aplicados son suficientes para satisfacer o no los deberes de dirección y supervisión consagrados en el art. $3^{\circ}$ in. $1^{\circ}$. En ese sentido, se le permite valorar la constitución, el objeto, el funcionamiento, la organización interna, la cultura corporativa y demás características relevantes de la organización.

En relación con lo anterior, si bien desde la dictación de la norma ha existido certeza sobre la no-obligatoriedad del art. $4^{\circ}$ de la LRPPJ, no ha existido la misma claridad sobre las consecuencias de esta interpretación. Por una parte, se acepta plenamente la posibilidad de implementar modelos atípicos de prevención de delitos. Sin embargo, los deberes de dirección y supervisión constituyen normas de comportamiento anteriores a la ley penal, que luego han sido cristalizadas y sancionadas a través del art. $3^{\circ}$ in. $1^{\circ}$ in fine de la LRPPJ. Las consecuencias inmediatas de esta diferenciación son valoradas a continuación.

\subsection{Valoración provisional}

Como corolario, es posible afirmar que el art. $3^{\circ}$ in. $1^{\circ}$ in fine de la LRPPJ establece un requisito de imputación que sanciona el incumplimiento de deberes de dirección y supervisión, con una pena para la organización. En conformidad con lo expuesto anteriormente, ${ }^{73}$ esta disposición debe encontrar su correlato en normas de comportamiento para justificar su punibilidad. Comúnmente, se puede leer que dicho fundamento estaría dado por el texto del art. $4^{\circ}$ de la LRPPJ, en tanto delinearía la conducta esperada que debe cumplir la organización para ser exenta de penalidad por delitos cometidos en su seno. Sin embargo, tal como se ha expuesto, el art. $4^{\circ}$ LRPPJ no es el único punto de análisis que deben considerar los tribunales al momento de resolver sobre la culpabilidad de la organización.

Pese a lo anteriormente razonado, en la jurisprudencia de tribunales no se ha asumido totalmente que los deberes de dirección y supervisión pueden ser acreditados por vías alternativas, al margen del modelo de prevención de delitos contemplado en el art. $4^{\circ}$ de la LRPPJ. Así, las sentencias, pese a admitir la posibilidad de "otras medidas" aptas para cumplir los deberes de dirección y supervisión, son vacilantes y carentes de fundamentación sobre el punto, contentándose simplemente con constatar la inexistencia del modelo del art. $4^{\circ}$ de la LRPPJ. ${ }^{74}$ Luego, el análisis respecto a si una persona jurídica imputada ha cumplido con sus deberes de dirección y supervisión, se reduce meramente a una revisión formal del hecho de contar con un modelo de prevención de delitos como el establecido en el art. $4^{\circ}$ de la LRPPJ, sin fundamentar (y en algunos casos incluso sin reconocer) la omisión de otras medidas o conductas capaces de cumplir con estos deberes.

Concordantemente, es posible acreditar un cumplimiento de los deberes de dirección y supervisión, y con ello eximir de responsabilidad a la persona jurídica, a través de un modelo de gobierno y supervisión que mantenga el funcionamiento de la organización en el marco de la legalidad. Y lo anterior, independiente que no se le bautice como "modelo de prevención de delitos" en la reglamentación interna o que no siga fielmente el art. $4^{\circ}$ de la LRPPJ. Si la

\footnotetext{
73 Acápite 1.3.

${ }^{74}$ Reparo que ya manifestaban NAVAS y JAAR (2018), p. 1039 y, más recientemente, ARTAZA (2019), p. 38.
} 
organización no se ha estructurado ni funcionado defectuosamente, no es posible reprocharle un defecto organizacional en el sentido dispuesto en el art. $3^{\circ}$ in. $1^{\circ}$ in fine de la LRPPJ.

Es indispensable recalcar la importancia de este punto, dado que el art. 342 lit. d) del Código Procesal Penal (en adelante el "CPP”), consagra la obligación para el juzgador de contemplar en la sentencia las "razones legales o doctrinales que sirvieren para calificar jurídicamente cada uno de los hechos y sus circunstancias y para fundar el fallo". Este requisito de fundamentación es de tal relevancia, que su incumplimiento constituye motivo absoluto de nulidad del juicio y de la sentencia conforme al art. 374 lit. e) del CPP. Y, ¿cómo podrá cumplir con esta norma una sentencia, si ni siquiera se realiza correctamente una diferenciación sobre las posibilidades de incumplimiento que admite el art. $3^{\circ}$ in. $1^{\circ}$ parte final de la LRPPJ?

En contraste, el Ministerio Público sí ha reconocido que el requisito de imputación de defecto de organización debe acreditarse en todo caso, estableciendo, al poco andar de la norma, una clara diferencia entre los objetos de prueba, cuando se está en presencia de modelos de prevención según el art. $4^{\circ}$ de la LRPPJ y cuando no. En el primer caso, el modelo de compliance implementado debe indagarse en cuanto a su realidad, efectividad e idoneidad, con el objeto de descubrir si realmente representa un cumplimiento de deberes de dirección y supervisión o un mero recurso formal de defensa. En el segundo caso, esto es en ausencia de un modelo de prevención, la actividad probatoria debe encaminarse a acreditar el requisito de imputación de defecto de organización, ${ }^{75}$ a través la prueba de incumplimiento de deberes de dirección y supervisión organizacionales.

La diferencia entre el requisito del incumplimiento de los "deberes de dirección” y los "modelos de prevención" se condice, por lo demás, con la naturaleza de unas y otras normas. Así, el peso de la prueba del incumplimiento de los deberes, en tanto requisito de imputación, debe recaer en los organismos persecutores ${ }^{76}$ mientras que la prueba de la implementación del modelo de organización, administración y supervisión, en tanto eximente de responsabilidad penal, corresponderá al defendido.

\section{Derecho comparado}

Para complementar el análisis realizado, resulta de utilidad revisar ordenamientos comparados que exhiban una regulación más profunda o una jurisprudencia consolidada en materia de defecto de organización. En este contexto, es posible anticipar que la regulación alemana presenta una interesante categorización de los deberes de dirección y supervisión, que hace conveniente su análisis. Por su parte, el ordenamiento español ha experimentado

\footnotetext{
75 “Ahora bien, la efectiva adopción e implementación del modelo de prevención siempre será objeto de investigación y prueba. En este sentido, conviene destacar que el hecho de cumplir la empresa formalmente con todos los requisitos que el art. $4^{\circ}$ establece para la adopción del modelo de prevención de delitos, no implica que esta haya implementado el modelo real, eficaz o idóneamente, lo cual será siempre objeto de investigación y prueba. [...] Asimismo, si la empresa no adoptó un modelo de prevención como el propuesto por la ley, ello no significa dar por cumplido este presupuesto de imputación, sino que necesariamente, aquel presupuesto deberá ser acreditado por el Ministerio Público”. FISCAL NACIONAL (2010), p. 7.

76 VAN WEEZEL (2010), p. 138. NEIRA (2016), p. 476.
} 


\section{Polít. Crim. Vol. 15, No 30 (Diciembre 2020), Art. 7, pp. 694-728 [http://politcrim.com/wp-content/uploads/2020/12/Vol15N30A7.pdf]}

una reforma muy reciente relacionada con el modelo de responsabilidad penal de las personas jurídicas, que hace prudente su consideración en este trabajo.

La metodología empleada al efecto será desde el enfoque funcional, ${ }^{77}$ que postula que sólo es posible comparar instituciones de los ordenamientos extranjeros que "desempeñen la misma tarea y cumplan idéntica función" "78 que la institución del ordenamiento interno que se pretende comparar. En este sentido, se han identificado como de interés el $\S 30$ de la Ley de Contravenciones alemana (en original Ordnungswidrigkeitengesetz, en adelante la "OWiG"), y el art. 31 bis del Código Penal español (en adelante el "CPe"), que a continuación se analizarán en cuanto a sus propias versiones del defecto de organización, con el objeto de extraer lecciones útiles para comprender el contenido de las normas de conducta del art. $3^{\circ}$ in. $1^{\circ}$ in fine de la LRPPJ.

\subsection{Alemania}

Según la legislación alemana vigente, las personas jurídicas y demás asociaciones de personas no pueden ser hechas penalmente responsables. Según la mayoría de la doctrina de ese país, las personas jurídicas y demás asociaciones de personas carecerían de la capacidad necesaria para actuar penalmente y de los atributos suficientes para sustentar un reproche de culpabilidad. ${ }^{79}$ Sin embargo, ello no significa que no puedan aplicarse sanciones de distinto carácter a las personas jurídicas. Ello ocurre a través del derecho contravencional que, según el $\S 1$ in. $1^{\circ}$ de la OWiG, sanciona actos antijuridicos y reprochables a través de multas y no con penas privativas de libertad. ${ }^{80}$ La más importante sanción contra personas jurídicas es la multa contravencional contemplada en el $\S 30$ de la OWiG.

\subsubsection{Deberes aplicables a la persona jurídica}

La figura antes descrita ordena la aplicación de una multa contravencional contra personas jurídicas y otras asociaciones de personas, en el supuesto que sus representantes (órganos, directorio, representantes u otros directivos) cometan un delito o una contravención, a través de la cual se incumplan los deberes o exista un enriquecimiento de la asociación. ${ }^{81}$ Particularmente relevante es este último requisito: el hecho de conexión sólo puede acarrear la imposición de una multa para la asociación, si este ha sido cometido a través del incumplimiento de los deberes aplicables a la persona jurídica o asociación de personas ( $\$ 30$ in. $1^{\circ}, 1^{\circ}$ alternativa, $\mathrm{OWiG}$ ) o, alternativamente, si la asociación se ha enriquecido con él o al menos su enriquecimiento haya sido intencionado ( $\$ 30$ in. $1^{\circ}, 2^{\circ}$ alternativa, $\left.\mathrm{OWiG}\right)$.

\footnotetext{
77 Para un panorama general sobre el método funcional de comparación y una crítica al efecto, véase a MICHAELS (2008), pp. 339 y ss. Compárese a FATEH-MOGHADAM (2011), pp. 44 y ss.

78 ZWEIGERT y KÖTZ (1996), p. 33. Para el concepto de la función y la primacía de la estructura de necesidades ante la función, véase a FATEH-MOGHADAM (2011), pp. 45 y ss.

${ }^{79}$ Sobre la capacidad de acción y culpabilidad de las personas jurídicas según la dogmática penal, véase BEDECARRATZ (2016), pp. 66 y ss. y pp. 79 y ss. respectivamente.

${ }^{80}$ Constituye un orden paralelo, que en principio se ubica "junto" al Derecho penal y no "debajo" de este. Así la sentencia del Tribunal Supremo alemán BGHSt 38, 138, 141. MITSCH (2018), p. 9.

${ }^{81}$ ROGALL (2018a), p. 525.
} 
En concordancia con lo anterior, la norma contempla un factor de conexión entre el delito y la persona jurídica, además de la posición del sujeto activo en la organización ${ }^{82}$ que puede consistir, alternativamente, en su enriquecimiento o, en lo que nos interesa, en la infracción de ciertos deberes aplicables específicamente a la persona jurídica o asociación de personas. Cabe entonces precisar, qué se entiende por esta clase de deberes.

Según la fundamentación del proyecto de ley de la OWiG, estos se refieren sólo a aquellos que se derivan para la persona jurídica o la asociación de personas de su ámbito especial de actividad, es decir, los "deberes relacionados con la actividad operacional". 83 A mayor abundamiento, las normas de conducta generales que se derivan de normativa penal tienen una validez general y no se derivan de la actividad operacional de las personas jurídicas. Sin embargo, en casos concretos pueden existir deberes especiales para las personas jurídicas en el contexto de su actividad operacional, que también estén cubiertos por tipos penales de aplicación general.

En tal sentido, es posible reconocer ciertos deberes que subyacen a delitos generales, pero que, debido a la actividad de la persona jurídica, pueden también fundamentar una sanción organizacional en caso de su vulneración en un contexto colectivo. Un ejemplo de lo anterior es el deber del empleador de proteger a su trabajador de riesgos en el lugar de trabajo. Tal como se especifica en la fundamentación del proyecto de ley de la OWiG: "Es por lo tanto factible, que por ejemplo una lesión o un homicidio culposo, perpetrado por un órgano, constituya el fundamento para la aplicación de una multa para una persona jurídica". ${ }^{84}$

En relación con lo anterior, el Derecho alemán exhibe una clasificación de deberes aplicables también a las personas jurídicas y asociaciones de personas, de acuerdo con las categorías de delitos que los concretizan. Esta clasificación puede ofrecer una primera pista, en relación con las clases de normas de conducta extrapenales que deben cumplir las personas jurídicas.

\subsubsection{Categorías de deberes de comportamiento}

En la primera categoría se incluyen los deberes de comportamiento correspondientes a los delitos especiales, entendiéndose por tales aquellos que sólo pueden cometer quienes poseen determinadas calidades o características especiales que la ley requiere para ser autor. ${ }^{85}$ Así, todos los delitos especiales aplicables a la persona jurídica como tal le imponen mandatos o prohibiciones y en esa calidad cristalizan deberes operacionales. Estas figuras son particularmente prevalentes en materia del Derecho penal económico, debido al influjo del Derecho regulatorio y el control de actividades económicas riesgosas de privados por parte del Estado.

En la práctica, los delitos o contravenciones especiales sancionan el incumplimiento de normas de conducta que se derivan de las posiciones especiales que ocupan las personas

\footnotetext{
${ }^{82}$ Sobre el problema de la posición de garante de estos sujetos HERNÁNDEZ (2013), pp. 333 y ss.

${ }^{83}$ Entwurf eines Gesetzes über Ordnungswidrigkeiten (OWiG), BT-Drucks. V/1269, p. 60.

${ }^{84}$ Entwurf eines Gesetzes über Ordnungswidrigkeiten (OWiG), BT-Drucks. V/1269, pp. 60 y ss.

${ }^{85}$ POLITOFF, MATUS y RAMÍREZ (2004), p. 187. BACIGALUPO (1999), p. 237. Lo anterior, sin importar si se trata de delitos especiales propios o impropios. Así ROGALL (2018a), p. 552.
} 


\section{Polit. Crim. Vol. 15, No 30 (Diciembre 2020), Art. 7, pp. 694-728 [http://politcrim.com/wp-content/uploads/2020/12/Vol15N30A7.pdf]}

jurídicas en la sociedad. Ello ocurre, por ejemplo, con su calidad de empleador, propietario de vehículos, productor o comercializador de bienes o servicios, o bien con su giro, como por ejemplo cuando opera como actor en el mercado de capitales. ${ }^{86}$ En todos estos casos, los deberes de dirección tienen como sustrato normas de conducta derivadas de la posición o actividad de la organización, y que tienen su correlato en la obligación de la persona jurídica de controlar el riesgo emanado de sus actividades y no de un riesgo meramente general o común.

La segunda categoría se identifica con la contravención especial contemplada en el $\S 130$ in. $1^{\circ}$ de la OWiG. ${ }^{87}$ Esta norma sanciona al titular de una empresa o negocio que incumple dolosa o imprudentemente deberes de supervisión, que son necesarios para impedir la infracción de deberes negociales o empresariales. ${ }^{88}$ En este caso, el injusto del hecho equivale a no tomar las medidas necesarias para evitar el incumplimiento de deberes negociales o empresariales, ${ }^{89}$ no propiamente en la contravención, que en este esquema se revela más bien como una condición objetiva para la imposición de una sanción. ${ }^{90}$ La propia ley especifica que estos deberes incluyen también el nombramiento, selección cuidadosa y control de personal de supervisión. Así, la conducta penal contemplada en esta segunda variante, la constituyen los deberes de vigilancia y supervisión internos que deben primar en las organizaciones, cuya extensión es variable según sus distintos tipos.

Esta categoría es la más relevante en la práctica, pues genera un efecto irradiante que alcanza no solo a sujetos con facultades de representación, dirección o control al interior de la organización, sino a sujetos que, sin estar incluidos como agentes del $\S 30$ in. $1^{\circ}$ de la $\mathrm{OWiG}$, sí están sujetos a la supervigilancia de los primeros. En este sentido, pese a que sujetos situados bajo el escalafón directivo de la organización no son capaces de irrogar directamente la responsabilidad del colectivo, debido al texto del $\S 30 \mathrm{in.} 1^{\circ}$ de la OWiG, sí pueden hacerlo en cuanto un representante o directivo de la persona jurídica o asociación haya incumplido con sus deberes de supervisión. De este modo, el $\S 130$ in. $1^{\circ}$ de la OWiG opera como una ventana que, subjetivamente, amplía el espectro de posibles autores de la organización; y, objetivamente, incorpora los deberes de supervisión y control internos como normas de conducta sancionables para la persona jurídica. ${ }^{91}$

La tercera y última categoría está constituida por los delitos comunes, entendiéndose por tales aquellos que no exigen una calidad determinada en la persona del autor y pueden ser

\footnotetext{
${ }^{86}$ ROGALL (2018a), pp. 552 y s.

${ }^{87} \S 130$ in. $1^{\circ}$ de la OWiG. "El que como titular de un negocio o empresa omite dolosa o imprudentemente las medidas de supervisión necesarias para evitar incumplimientos en el negocio o empresa de deberes que corresponden al titular y cuya infracción esté amenazada con una pena o una multa contravencional, incurre en una contravención si se comete una infracción que, con la vigilancia debida, se hubiera impedido o dificultado considerablemente. Entre las medidas de vigilancia necesarias se incluye también el nombramiento, la selección cuidadosa y el control de personal de vigilancia.” Traducción del autor. Sobre la materia BOCK (2013), p. 109 y HERNÁNDEZ (2012), p. 86.

${ }^{88}$ BOCK (2013), pp. 109 y ss. Esta obligación pesa sobre los agentes contemplados en el $\S 30$ in. $1^{\circ}$ de la OWiG. ENGELHART (2012), p. 401.

${ }^{89}$ ROGALL (2018b), p. 1827.

${ }^{90}$ HERNÁNDEZ (2012), p. 86.

${ }^{91}$ BEDECARRATZ (2016), p. 223.
} 
cometidos por cualquiera. ${ }^{92}$ Es decir, un delito o una contravención común cometida por el órgano o su representante puede, al mismo, desencadenar la responsabilidad de la persona jurídica. En estos casos y con el objeto de actuar como un filtro, la norma restringe los delitos comunes cometidos por el órgano o su representante capaces de irrogar la responsabilidad del colectivo, solamente en cuanto estos delitos impliquen, al mismo tiempo, una infracción a deberes relacionados con la actividad operacional de la persona jurídica o asociación de personas.

En relación con lo anterior, la pregunta respecto a cuándo un delito común significa al mismo tiempo el incumplimiento de un deber relacionado con la actividad operacional de la persona jurídica (acarreando, en consecuencia, también la responsabilidad del colectivo), es especialmente controvertida en la literatura especializada. ${ }^{93}$ Sin embargo, una interpretación acorde con la ratio legis que sustentó la reforma legislativa del año 2007 de los $\$ \S 30$ y 130 de la $\mathrm{OWiG}^{94}$ permite aseverar, que las personas jurídicas solamente pueden ser hechas responsables por contravenciones o delitos, que emanen del incumplimiento de su obligación de controlar sus riesgos. En este sentido, el deber de intervención del órgano o representante dice relación con la responsabilidad de controlar los riesgos objetivos y subjetivos emanados de la actividad negocial. ${ }^{95}$

De lo anterior se puede colegir, que la infracción de deberes debe darse en el contexto de la gerencia o dirección de la organización y tener una relación con las actividades desempeñadas por esta. Por ejemplo, existiría un incumplimiento de dichas obligaciones, en el caso de una empresa desarrolladora de software para clientes, si sus dependientes, durante el cumplimiento de esta función de desarrollo, accediesen ilícitamente a los datos personales de los primeros. Por el contrario, ello no se verificaría si se tratase del técnico informático de una oficina de arquitectos que ocasionalmente comete el mismo ilícito respecto de los clientes de la oficina. ${ }^{96}$ En consecuencia, las personas jurídicas serán responsables por delitos o contravenciones comunes que se identifiquen con la infracción de deberes derivados de su ocupación comercial, lo que encuentra su fundamento en el deber de conducir los propios negocios sin generar daños a terceros.

\subsection{España}

El 23 de diciembre de 2010, la Ley Orgánica (en adelante la “L.O.”) 5/2010 incorporó el nuevo art. 31 bis al CPe, implementando así la responsabilidad penal de las personas jurídicas en el ordenamiento interno español. En virtud de lo anterior, España se incorporó al considerable listado de Estados que contemplan una responsabilidad penal de personas jurídicas. ${ }^{97}$ Posteriormente, en virtud de la L.O. 1/2015 del 30 de marzo de 2015, se modificó

\footnotetext{
92 POLITOFF et al. (2003), p. 187.

93 Véase por todos a HERNÁNDEZ (2013), pp. 333 y ss. Un resumen de la disputa en ROGALL (2018b), pp. 1840 y ss. y en especial a partir de pp. 1842 y ss.

94 BGBl. I, p. 1786

${ }^{95}$ ROGALL (2018a), p. 552; y más específicamente en ROGALL (2018b), p. 1845. Sin perjuicio de lo expuesto, como toda norma sancionatoria, la conexión con la actividad operacional de la persona jurídica debe interpretarse restrictivamente. HERNÁNDEZ (2013), p. 335.

${ }^{96}$ E-StrÄndG, BT-Drucks. 16/3656, p. 14.

${ }^{97}$ Véase, nota al pie $\mathrm{N}^{\circ} 1$.
} 


\section{Polít. Crim. Vol. 15, № 30 (Diciembre 2020), Art. 7, pp. 694-728 [http://politcrim.com/wp-content/uploads/2020/12/Vol15N30A7.pdf]}

profundamente este sistema de responsabilidad, reestructurando el referido art. 31 bis del CPe e incorporando tres nuevos artículos (art. 31 ter, 31 quáter y 31 quinquies del CPe), que especifican y complementan el marco de aplicación de la responsabilidad penal colectiva. Finalmente, a través de la L.O. 1/2019 del 20 de febrero de 2020, se amplió el catálogo de conductas delictivas por las que las organizaciones pueden ser hechas penalmente responsables, entre otros ajustes a los marcos de punibilidad de los delitos de conexión.

Producto de las mencionadas reformas, el sistema de imputación ha alcanzado un alto nivel de complejidad. En su actual expresión, prevé una doble vía de atribución de pena. Por una parte, el art. 31 bis $\mathrm{N}^{\circ} 1$ apartado a) del CPe sanciona a la persona jurídica por la comisión de delitos a través de sus representantes legales o por aquellos que, actuando individualmente o como parte de un órgano de esta, están autorizados para tomar decisiones en su nombre, u ostentan facultades de organización y control en su seno. La segunda modalidad de atribución, consagrada en el art. 31 bis $\mathrm{N}^{\circ} 1$ apartado b) del CPe, combina dos presupuestos copulativos: la comisión de un delito por un individuo bajo la autoridad de las personas físicas nombradas en el apartado a) y que los hechos hayan podido realizarse por existir incumplimiento grave de "los deberes de supervisión, vigilancia y control de su actividad" atendidas las concretas circunstancias del caso. ${ }^{98}$

En este contexto, resulta interesante resaltar el rol que cumple el compliance en el modelo de imputación, la naturaleza de los deberes de supervisión, vigilancia y control, y la interacción de ambos elementos con normas de naturaleza extrapenal en el sistema español.

\subsubsection{Contenido e incidencia de los modelos de organización y gestión}

En ambas modalidades de atribución (apartados a) y b) del art. 31 bis $\mathrm{N}^{\circ} 1$ del CPe) se prevé la posibilidad de exención de las personas jurídicas a través de programas de cumplimiento normativo, denominados "modelos de organización y gestión", que tienen por objeto prevenir delitos de la misma naturaleza del que fue cometido o reducir de forma significativa el riesgo de su comisión. Los programas deben satisfacer en todo caso el catálogo de requisitos mínimos contemplado en el art. 31 bis $\mathrm{N}^{\circ} 5 \mathrm{CPe}$. Sin embargo, en uno y otro caso (art. 31 bis $\mathrm{N}^{\circ} 2$ y art. 31 bis $\mathrm{N}^{\circ} 4$, respectivamente), los programas son consagrados de manera distinta 99 $\mathrm{y}$, además, se ven flanqueados por requisitos diversos. ${ }^{100}$

En cuanto a su contenido mínimo, el art. 31 bis $N^{\circ} 5$ CPe exhibe una estructura similar a las cuatro fases ya observadas en el modelo de prevención de delitos de la LRPPJ: identificación y prevención de riesgos, más detección y sanción de contravenciones. ${ }^{101}$ En efecto, el $1^{\circ}$

\footnotetext{
${ }^{98}$ Análisis de los requisitos de imputación en PÉREZ (2017), pp. 89 y ss. Confróntese con FEIJOO (2016), pp. 109 y ss. Comparativamente, las condiciones establecidas en el art. 31 bis $\mathrm{N}^{\circ} 1$ lit. a) son menos estrictas que las establecidas por el art. $3^{\circ}$ in. $1^{\circ}$ de la LRPPJ, pues no contemplan un incumplimiento de deberes equivalente a un defecto de organización como requisito de imputación. Sin embargo, sí se contempla el cumplimiento de deberes por la vía de la eximente de responsabilidad del art. 31 bis $\mathrm{N}^{\circ} 2 \mathrm{CPe}$, como se verá a continuación.

99 Sobre los criterios de "eficacia" e "idoneidad" y valoración en una y otra variante de imputación GUTIÉRREZ (2015), pp. 1 y ss.

100 Así, "la principal consecuencia de esta diferenciación en dos vías de imputación es que las condiciones o los requisitos para la exención de responsabilidad son distintos”. FEIJOO (2016), p. 110.

101 Véase acápite 2.1.
} 
requisito exige la identificación de actividades expuestas al riesgo de comisión de delitos, concentrando de este modo el análisis de la persona jurídica en aquellos riesgos que le son previsibles, conforme al ámbito de sus operaciones. ${ }^{102}$ Se trata aquí de elaborar un "mapa de riesgos" a los que se ve expuesta la persona jurídica, según el potencial delictivo y las conductas ilícitas que a partir de ellos pueden originarse, ${ }^{103}$ catalogándolos según probabilidad de comisión e impacto potencial en caso de verificarse en base a criterios cuantitativos y cualitativos. ${ }^{104}$

En cuanto a la fase de prevención de riesgos, el $2^{\circ}$ requisito ordena establecer protocolos y procedimientos que concreten el proceso de formación de la voluntad de la persona jurídica, de adopción de decisiones y de su ejecución conforme a aquellos. Lo anterior implica formalizar los mecanismos de formación de voluntad y de toma de decisiones, para poder establecer controles preventivos y reactivos al efecto. ${ }^{105}$ En un espíritu similar, el $3^{\circ}$ requisito ordena el establecimiento de modelos de gestión de recursos financieros adecuados para prevenir los delitos respectivos. Lo anterior resulta fundamental, tanto para garantizar financieramente el funcionamiento del modelo, como para controlar conductas criminógenas que se sirvan de esos mismos recursos para perpetrar delitos "en" y "desde" la organización. ${ }^{106}$

La tercera fase de detección se encuentra consagrada en el $4^{\circ}$ requisito que, en miras de garantizar la eficacia del modelo, prevé la obligación de informar de riesgos e incumplimientos al organismo encargado de su supervigilancia. ${ }^{107}$ Estos canales de denuncia o de whistleblowing constituyen un elemento clave del modelo de prevención, ${ }^{108}$ que garantizan a los denunciantes su confidencialidad, y permitan a los organismos internos intervenir a tiempo y tutelar el efectivo cumplimiento del modelo. En estrecha relación con lo anterior, el $5^{\circ}$ requisito materializa la fase de "sanción" del modelo de organización y gestión. En este sentido, si bien la norma española no lo exige expresamente, la más elemental determinación de la responsabilidad disciplinaria exige que las normas estén objetivadas a través de una disposición legal o en el convenio colectivo respectivo. ${ }^{109}$

Como se puede ver, el art. 31 bis $\mathrm{N}^{\circ} 5$ del CPe establece una serie de requisitos, que se limitan a establecer genéricamente lo qué deben incluir los modelos, pero no "cómo" deben satisfacerse. Al igual que en el caso chileno, las disposiciones no solo extrapenales, sino también infra legales y de carácter sectorial cobran especial relevancia, pues vienen en

\footnotetext{
102 NIETO (2013), p. 45.

103 PÉREZ (2017), p. 110

${ }^{104}$ Ver metodología expuesta en ARTAZA (2013b), pp. 557 y ss.

105 NEIRA (2016), p. 471.

106 PÉREZ (2017), p. 112.

${ }^{107} \mathrm{El}$ art. 31 bis $\mathrm{N}^{\circ} 2-2$ establece que las funciones de supervisión del funcionamiento y cumplimiento del modelo deben haber sido confiadas, a un organismo con poderes autónomos de iniciativa o control, o dotado legalmente de la función de supervisar la eficacia de controles internos de la persona jurídica. Esto es requisito para la exención en la primera vía de imputación (art. 31 bis $\mathrm{N}^{\circ} 1$ lit. a) del CPe), mas no en la segunda.

${ }^{108}$ FGE (2016), p. 45. Compárese procedimientos de denuncia contemplados en el art. $4^{\circ} \mathrm{N}^{\circ} 3$ lit. d) de la LRPPJ, ver acápite 2.1.

109 PÉREZ (2017), p. 115. NEIRA (2016), pp. 473 y ss. Por último, la norma también requiere la revisión periódica y actualización del programa de compliance, con el fin de mantener su vigencia en el tiempo.
} 


\section{Polít. Crim. Vol. 15, No 30 (Diciembre 2020), Art. 7, pp. 694-728 [http://politcrim.com/wp-content/uploads/2020/12/Vol15N30A7.pdf]}

complementar los requisitos contemplados en el art. 31 bis $\mathrm{N}^{\circ} 5$ del CPe. En este sentido, existen estándares nacionales e internacionales que, a través de un catálogo de normas objetivas, especifican y otorgan mayor determinación a los modelos legales de compliance. ${ }^{110}$

Así, en cuanto a directrices generales, cobran validez las contenidas en la norma ISO 19600: 2015 "Sistemas de gestión de compliance. Directrices", así como la norma UNE"11 19601: 2017 "Sistemas de gestión de compliance penal", que establecen directrices para la organización y gestión de programas de compliance, tales como la planificación de riesgos o evaluación del sistema de cumplimiento. ${ }^{112}$ En materia de riesgos delictivos específicos son también relevantes los estándares dedicados a cada uno de ellos, tales como la norma UNE 19602: 2019 "Sistemas de gestión de compliance tributario.", que tiene especial relevancia en materia de contravenciones y delitos tributarios, o la norma ISO 37001: 2016 "Sistemas de Gestión Anti-Soborno", especialmente enfocada en el combate del soborno y en la promoción de una cultura empresarial ética.

En relación con la vinculatoriedad de estos estándares, se entiende que son plenamente voluntarios para las personas jurídicas. ${ }^{113}$ Así, las empresas pueden optar por certificarse en base a estas normas, generando documentos que puede aportarse como un antecedente acerca del cumplimiento, por parte de la persona jurídica, de las obligaciones de compliance contempladas en el art. 31 bis $\mathrm{N}^{\circ} 5$ del CPe, lo cual, a su vez, puede aportar a su exención por la vía del art. 31 bis $\mathrm{N}^{\circ} 2$ o $\mathrm{N}^{\circ} 4$ del CPe, según sea el caso. ${ }^{114}$ Así, tienen por una parte una función general de determinación y estandarización y, por otra, una específica de servir como pauta para lograr una atenuación o exención de responsabilidad penal. Sin embargo, los referidos estándares no pueden, por sí solos, asumir un rol vinculante en cuanto a la implementación de los sistemas de organización y gestión contemplados en la ley.

\subsubsection{Los deberes de supervisión, vigilancia y control: su función y contenido}

De los anteriores "modelos de organización y gestión”, válidos como eximente de responsabilidad penal en ambas vías de imputación, debe distinguirse el incumplimiento grave de "deberes de supervisión, vigilancia y control", como requisito de imputación de la segunda variante de comisión. El contenido de este requisito es especialmente relevante a efectos de la determinación de las normas de comportamiento de la persona jurídica, como se verá.

Históricamente, la redacción original de la norma establecía la atribución de responsabilidad organizacional, por delitos cometidos por quienes han podido realizar los hechos "por no haberse ejercido sobre ellos el debido control". La reforma implementada por la L.O. 1/2015 amplió el objeto de los deberes desde una simple obligación de "debido control" a "deberes

\footnotetext{
${ }^{110}$ En relación con su indeterminación y complemento a través de normativa extrapenal BEDECARRATZ (2018), pp. 224 y ss. y NIETO (2012), pp. 124 y ss.

111 “Asociación Española de Normalización”, institución enfocada en la normalización de diversas actividades y procesos.

112 PÉREZ (2017), p. 123.

113 Salvo que se referencie su contenido en disposiciones legislativas, caso en el cual asumirán cierta fuerza normativa.

${ }^{114}$ Crítica del sistema de certificaciones en MATUS (2017), pp. 41 y s.; y NIETO (2012), pp. 124 y ss.
} 
de supervisión, vigilancia y control". Además, especificó la falta desde una simple omisión consistente en "no haberse ejercido" a derechamente un incumplimiento, y graduó el defecto exigido como grave. ${ }^{115}$ Así, la reforma delimitó los contornos del defecto de organización, ofreciendo mayores elementos para concretizar su contenido.

En cuanto a su función, el requisito de imputación es una importante regla para la atribución de responsabilidad al colectivo por los actos de sus dependientes. Concretamente, exige como primer supuesto una relación de superior/subordinado, a través de la existencia de un deber de supervisión, vigilancia y control del sujeto en posición directiva o apical, sobre el autor individual. Además, se establece un segundo supuesto, relacionado con que el incumplimiento debe presentarse "atendidas las concretas circunstancias del caso", estableciendo una regla de razonabilidad en la interpretación del contexto en que se da el incumplimiento. El CPe emplea requisitos típicos altamente restrictivos, que son complejos de subsumir en el caso concreto.

Llegados a este punto, cabe atender al contenido de estos deberes, previa constatación de lo evidente: el CPe no ofrece una definición de deberes de supervisión, vigilancia y control ni una delimitación de su alcance, lo que constituye uno de los principales escollos del sistema de imputación. ${ }^{116}$ Esta imprecisión se originó a partir de la introducción del art. 31 bis del CPe en 2010 y, pese a numerosos cambios legislativos incorporados por la L.O. 1/2015, aun no tiene una respuesta clara. ${ }^{117}$

A primera vista, el modelo de organización y gestión del art. 31 bis $\mathrm{N}^{\circ} 5$ del CPe constituiría el contenido de los deberes mencionados. Sin embargo, esta idea no es correcta pues, en primer lugar, la ley ha previsto el modelo de organización y gestión como el contenido necesario de otro elemento: las exenciones de punibilidad contempladas en el art. 31 bis $\mathrm{N}^{\mathrm{o}} 2$, condición $1^{\mathrm{a}}$, y el art. 31 bis $\mathrm{N}^{\mathrm{o}} 4$ del CPe. Las obligaciones de supervisión, vigilancia y control contempladas en el art. 31 bis $\mathrm{N}^{\circ} 1$ lit. b) CPe constituyen, en cambio, un requisito del tipo de la organización, correspondiente a la conducta de la persona jurídica. Consecuentemente, el cumplimiento de estos deberes no deriva en la juridicidad de la conducta, sino que en su atipicidad: la conducta organizacional nunca alcanzó a completarse. $^{118}$

En segundo lugar, el art. 31 bis $\mathrm{N}^{\circ} 5$ CPe se prevé como eximente también para la modalidad contemplada en el art. 31 bis $\mathrm{N}^{\circ} 1$ lit. b) del CPe, esto es, la comisión por un sujeto subordinado. En este sentido, si el art. 31 bis $\mathrm{N}^{\circ} 5$ del CPe fuese el contenido de estos deberes de supervisión, vigilancia y control, la función del art. 31 bis $\mathrm{N}^{\circ} 4$ del CPe sería inexistente, pues la persona jurídica ya quedaría exenta por vía del art. 31 bis $\mathrm{N}^{\circ} 1$ lit. b) del CPe. Tomar

\footnotetext{
115 FERNÁNDEZ (2019), p. 3.

116 PÉREZ (2017), p. 99.

${ }^{117}$ Ello, a pesar de la declaración del título III del preámbulo de la L.O. 1/2015, que la reforma realizaría una mejora técnica "con la finalidad de delimitar adecuadamente el contenido del «debido control»".

118 BEDECARRATZ (2016), pp. 280 y ss. FERNÁNDEZ (2019), pp. 15 y ss.
} 


\section{Polit. Crim. Vol. 15, No 30 (Diciembre 2020), Art. 7, pp. 694-728 [http://politcrim.com/wp-content/uploads/2020/12/Vol15N30A7.pdf]}

en consideración los modelos de organización y gestión como único contenido de los deberes de dirección, vigilancia y control sería, en consecuencia, redundante. ${ }^{119}$

Una solución más acorde, postula que estos deberes hacen referencia a los ya conocidos deberes de control de las actividades de los subordinados, cuya ausencia haya posibilitado el delito del subordinado. ${ }^{120}$ A mayor abundamiento, la normativa administrativa, comercial o civil establece diversas obligaciones de control, en algunos casos genéricas y en otros específicas, que tienen por objeto regular la actividad de la empresa y los riesgos que ella conlleva. ${ }^{121} \mathrm{La}$ fuente de estas obligaciones debe indagarse en concordancia con los delitos a los cuales se les asocia:

1. Por una parte, existen tipos delictivos vinculados a actividades organizacionales que establecen obligaciones específicas de control, con procedimientos y obligaciones que regulan el actuar de la organización. ${ }^{122}$

2. Por otra parte, otras figuras delictivas no poseen normativa de soporte ni cuentan con un contexto regulatorio. ${ }^{123}$

En gran medida y derivado de esta diferenciación es que se conciben, por una parte, obligaciones genéricas de control (pertenecientes a la regulación mercantil o civil), que concretizan el deber genérico de supervisar, consustancial al ejercicio de potestades sobre otras personas. Ejemplo de lo anterior son la responsabilidad de dueños o directores de una empresa "por los perjuicios causados por sus dependientes en el servicio de los ramos en que los tuvieran empleados, o con ocasión de sus funciones" (art. 1903 in. $4^{\circ}$ del Código Civil español), así como los deberes generales de diligencia de los administradores, tendientes a adoptar las medidas necesarias para la buena dirección y control de la sociedad, contemplados en el art. 225 de la Ley de Sociedades de Capital española.

Por otra parte, también se conciben obligaciones específicas de control derivadas de la regulación sectorial, originadas en el marco de la intervención estatal. En este caso, el marco de los deberes de supervisión, vigilancia y control están dados por esta, que gradúa su calificación como contravención o como conducta delictiva, dependiendo del grado del incumplimiento. $^{124}$

De esta forma, los deberes de supervisión, vigilancia y control a los que alude la norma, se identificarían con estos deberes de control fijados por normativa extrapenal, sean estos de carácter genérico (civil y mercantil) o específico (regulatorio y administrativo). Así, el

\footnotetext{
${ }^{119}$ PÉREZ (2017), pp. 99 y s., considera que "los deberes" se refieren a la adopción de "medidas para prevenir, detectar o reprimir la comisión de delitos como el que efectivamente se cometió", esto es, si el modelo es apto en concreto para prevenir el delito cometido. Compárese con FEIJOO (2016), pp. 112 y ss.

${ }^{120}$ SILVA (2018), p. 195. Sobre la posición de garante del empresario consultar la misma obra, pp. 198 y ss.

${ }^{121}$ FERNÁNDEZ (2019), p. 5. Riesgos penales que emanan de su ya conocido potencial criminógeno, y que la organización tendría obligación, a través de sus directivos, de controlar; SILVA (2018), pp. 212 y s.

${ }^{122}$ Ejemplos de lo anterior son actividades extractivas que tienen su regulación en normativa medioambiental que, a su vez, contemplan hechos de conexión en la norma española.

${ }^{123}$ Un ejemplo de ello serían delitos de corrupción de menores o la estafa FERNÁNDEZ (2019), pp. 5 y s.

124 FERNÁNDEZ (2019), pp. 6 y ss. Véase especialmente la categorización de los deberes según hecho de conexión en la tabla 1 , pp. 9 y ss.
} 
incumplimiento de una obligación específica de control (unida a los demás requisitos del art. 31 bis $\mathrm{N}^{\circ} 1$ lit. b) del CPe) acarrearía, directamente, la responsabilidad del ente, mientras que la de una genérica lo haría sólo en caso de que el superior conoció de la irregularidad y estuvo en posición de evitar el delito. ${ }^{125}$

\subsection{Valoración provisional}

Si bien tanto en la regulación alemana como en la española se contemplan obligaciones de supervisión, existen marcadas diferencias entre las contempladas en el art. 31 bis $\mathrm{N}^{\circ} 1$ lit. b) del $\mathrm{CPe}$ y en el $\S 30$ de la OWiG, en las que conviene detenerse un momento.

Pese a no existir ninguna especificación concreta de la violación de los deberes de supervisión en ambos casos, la jurisprudencia alemana ha definido los contornos del incumplimiento del deber de supervisión tomando como base el $\S 130$ de la OWiG, expandiéndolos sobre la base de los deberes relacionados con las obligaciones negociales de la organización. ${ }^{126}$ El Derecho español, por su parte, no posee una norma comparable al $\S 130$ de la OWiG y, por lo tanto, no ha existido un marco positivo para el desarrollo del incumplimiento de "deberes de supervisión, vigilancia y control" en ese sistema jurídico. ${ }^{127}$ Con todo, las posturas doctrinales expuestas proponen una correcta interpretación del requisito de imputación contemplado en el art. 31 bis $\mathrm{N}^{\circ} 1$ lit. b) del $\mathrm{CPe}$, que le dota de contenido práctico.

Los razonamientos y principios delimitados son, a nuestro juicio, transponibles al ordenamiento jurídico chileno. En este sentido, en unos y otros ordenamientos se sanciona el incumplimiento de deberes, sin que del texto legal pueda extraerse su contenido, debiendo encontrarse su fuente en normas de comportamiento extrapenales. Luego, la importancia de una distinción clara tiene una relevancia práctica esencial para la decisión de los casos y para la correcta aplicación de la justicia. A continuación, se propone una forma cómo debiera efectuarse dicha diferenciación.

\section{Hacia una propuesta de solución}

Como ya se ha demostrado en los capítulos anteriores, el defecto de organización no se agota en el incumplimiento de los modelos típicos de cumplimiento normativo. En realidad, constituye una categoría de imputación propia, correspondiente al incumplimiento de reglas

\footnotetext{
125 FERNÁNDEZ (2019), p. 13. En un sentido similar DEL ROSAL (2011), p. 91; BEDECARRATZ (2016), p. 281. Esta solución no había encontrado eco en parte de la literatura española, por ejemplo ROBLES (2012), p. 356, nota al pie $\mathrm{N}^{\circ} 58$ y DEL ROSAL (2011), p. 90. Se argumenta que la infracción de estos deberes ya podía ser sancionada a través del art. 31 bis. $\mathrm{N}^{\circ} 1$ del CPe (concretamente, por vía de la mera omisión de un directivo de realizar una acción para evitar un hecho delictivo por parte de un subordinado). Sin embargo, esta crítica pasa por alto, que los deberes que establece este tipo de normativa son normas de conducta cuyo destinatario es la organización o persona jurídica, y son cumplidos solo vicarialmente por el individuo en lugar de ella. Por lo tanto, si bien es cierto son ejecutados físicamente por los agentes en posición directiva, los procedimientos y obligaciones corresponden formal y materialmente a la persona jurídica como tal. Crítica en CARBONELL (2011), pp. 342 y s.

${ }^{126}$ ROGALL (2018b), pp. 1827 y ss.

${ }^{127}$ Crítica en ROBLES (2012), p. 356.
} 


\section{Polit. Crim. Vol. 15, No 30 (Diciembre 2020), Art. 7, pp. 694-728 [http://politcrim.com/wp-content/uploads/2020/12/Vol15N30A7.pdf]}

de comportamiento extrapenales, que tienen por destinatarias a las organizaciones como tales. Teniendo presente lo anterior, la determinación del contenido de estos deberes constituye un desafío interpretativo, del cual depende la correcta fundamentación de las sentencias. En este contexto, es posible aplicar reglas para desentrañar dicho contenido, sobre la base de la experiencia internacional en la materia.

El primer paso al efecto, es volver al telos o la finalidad originaria que fundamenta la responsabilidad penal de las personas jurídicas: impulsar a organizaciones a autorregularse en el ámbito de sus actividades, para impedir o disminuir el riesgo de comisión de actividades delictivas en su seno. ${ }^{128}$ En concordancia con lo anterior, la obligación de prevenir el delito debe estar vinculada con el ámbito de operación de negocios de la organización (o si se prefiere, el "giro" de la sociedad), en tanto es este el ámbito en el cual contrae la responsabilidad social de controlar el riesgo creado por su propia actividad.

En nuestra opinión, la persona jurídica no contrae el deber de supervisar o controlar riesgos atípicos que se aparten del ámbito negocial de la organización. Si se aplica la teoría del delito omisivo, ${ }^{129}$ la función de garante de vigilancia que asume la organización respecto de los hechos de sus dependientes ${ }^{130}$ no rige a todo evento, sino que se encuentra condicionada objetivamente por el ámbito de su ocupación social. ${ }^{131}$ Asumir lo contrario, equivaldría a una potencial responsabilidad de la organización por cualquier clase de riesgo extendiendo, desproporcionadamente, las obligaciones de control de la persona jurídica.

Derivado de lo anterior, el segundo paso para determinar el contenido de los deberes organizacionales consiste en realizar una derivación de los riesgos que presentan delitos determinados y el marco regulatorio existente en su caso para prevenirlos o perseguirlos. En este sentido, en línea con las experiencias alemana y española, resulta prudente hacer una distinción en cuanto a la especie de delitos y los deberes respectivos por los cuales puede ser hecha responsable la persona jurídica.

\subsection{Deberes de dirección y supervisión vinculados a normativa regulatoria}

En el Derecho chileno están incluidas, hasta el momento, alrededor de una docena de figuras delictivas de distinta índole, que pueden ser agrupadas para estos efectos en delitos de corrupción, terroristas, medioambientales, económicos y comunes. Naturalmente, delitos de diversa naturaleza se insertan en contextos de mayor o menor regulación sectorial (piénsese en un delito medioambiental versus una receptación). Consecuentemente, existen delitos acompañados de una abundante normativa regulatoria que, a su vez, impone una serie de deberes y obligaciones normalmente consagrados a disminuir contravenciones menores, evitando así una lesión o puesta en peligro de bienes jurídicos valiosos para la sociedad. ${ }^{132}$

\footnotetext{
128 Acápite 1.1.

${ }^{129}$ Fundamentación en SILVA (2018), pp. 193 y ss.

${ }^{130}$ HERNÁNDEZ (2010), p. 225. COLLADO (2013), pp. 166 y ss.

${ }^{131}$ En línea con la evolución del $§ 30$ OWiG, expuesta capítulo 3.1.2.

${ }^{132}$ A esta familia de delitos pertenecen verbigracia el de lavado de activos, cohecho, financiamiento del terrorismo y aquellos delitos medioambientales recientemente incorporados al art. $1^{\circ}$ de la LRPPJ.
} 
Para esta clase de delitos, los deberes de dirección y supervisión se traducen en el establecimiento de un sistema interno en concordancia con la regulación sectorial, destinado a garantizar su cumplimiento y eliminar o reducir contravenciones por parte de la organización. En caso de que un dependiente cometa un delito imputable a la persona jurídica en las materias afectas a regulación, la observancia de sus obligaciones regulatorias puede ser argumentada por parte de la organización como un cumplimiento de sus deberes de dirección y supervisión, y que el hecho no ha sido consecuencia de su incumplimiento en la materia. Conforme a lo que hemos argumentado, lo anterior es válido, incluso, si no se presenta un modelo de compliance como el establecido en el art. $4^{\circ}$ de la LRPPJ.

En este sentido, el juez abocado a resolver si una persona jurídica ha cumplido o no con sus deberes de dirección, deberá revisar si la persona jurídica a la que se le imputa un hecho de conexión, ha satisfecho la regulación sectorial aplicable en el contexto del hecho de conexión imputado, ha mantenido el orden interno de la organización y disminuido el riesgo de contravenciones. Luego, conforme al mayor o menor cumplimiento regulatorio demostrado por la organización, podrá decidir si ha cumplido o no con los deberes que sanciona el art. $3^{\circ}$ in. $1^{\circ}$ in fine de la LRPPJ. ${ }^{133}$

\subsection{Deberes generales de dirección y supervisión}

Por otra parte, existen otros tipos de delitos de carácter general o común, que no están flanqueados por normativa regulatoria complementaria. ${ }^{134}$ En estos casos, no es posible recurrir a normativa sectorial que ayude a determinar el contenido de los deberes de dirección y supervisión de la organización, encaminados a reducir el riesgo de comisión de delitos comparable, por ejemplo, con una Ley $\mathrm{N}^{\circ} 19.913$ en materia de lavado de activos.

En estos casos, el contenido del defecto de organización está dado por normativa de dirección y supervisión de carácter general aplicable a las distintas clases de personas jurídicas. En otras palabras, es necesario volver la mirada a los diversos principios de responsabilidad por hechos de terceros, obligaciones de supervisión y control específicas y demás normativa civil y/o mercantil que imponga deberes de organización internos. ${ }^{135}$ En el Derecho chileno, ello puede estar representado, por ejemplo, por el art. 184 del Código del Trabajo, que establece la responsabilidad del empleador por los hechos de sus trabajadores, o el art. 2320 del Código Civil que sanciona un deber general de cuidado respecto de ciertas personas.

\footnotetext{
${ }^{133}$ Por ejemplo, si a una persona jurídica se le imputa la comisión directa e inmediatamente en su interés o para su provecho, por parte de uno de sus agentes con facultades generales de administración, del delito de lavado de activos; el juez deberá observar si esa misma entidad ha practicado las denuncias de operaciones sospechosas correspondientes (art. $3^{\circ}$ in. $1^{\circ}$ de la Ley $\mathrm{N}^{\circ} 19.913$ ), si ha resguardado los registros correspondientes durante el plazo legal de 5 años (art. $5^{\circ}$ Ley $\mathrm{N}^{\circ}$ 19.913), entre otros. En ese sentido, la actividad de la fiscalía deberá estar enfocada en categorizar las obligaciones regulatorias en la especie, acreditar si se han cumplido en la práctica y, en caso de contravención, argumentar la equivalencia entre esta y la falta de deberes de dirección y supervisión (y con ello con un defecto de organización) de la persona jurídica.

${ }^{134}$ Los delitos que pertenecen a esta clase son el de receptación, los incorporados en virtud de la Ley $\mathrm{N}^{\circ} 21.121$, a saber: negociación incompatible, corrupción entre particulares, apropiación indebida y administración desleal, y la obtención fraudulenta de prestaciones estatales a causa del COVID-19 contemplado en el art. 14 de la Ley $\mathrm{N}^{\circ} 21.227$ del 6 de abril de 2020.

${ }^{135}$ En línea con lo planteado a propósito de España, véase acápite 3.2.2.
} 


\section{Polit. Crim. Vol. 15, No 30 (Diciembre 2020), Art. 7, pp. 694-728 [http://politcrim.com/wp-content/uploads/2020/12/Vol15N30A7.pdf]}

Sin embargo y más allá de disposiciones aisladas, el conjunto de normas absolutamente esencial en materia de deberes de dirección y supervisión, es el que regula los gobiernos corporativos de las distintas clases de personas jurídicas. Sin perjuicio que no existe un concepto unívoco, una primera acepción los relaciona con "los medios internos por los cuales son operadas y controladas las corporaciones." "136 Más concretamente, el concepto dice relación con la gobernanza, dirección y supervisión de organizaciones, ${ }^{137}$ que tienen por objeto establecer un sistema interno de conciliación de intereses, tendiente a resguardar los derechos de sus integrantes y de terceros. ${ }^{138}$

En concordancia con lo anterior, los principios de buen gobierno corporativo iluminan transversalmente los sistemas de responsabilidad penal de las personas jurídicas, y resultan fundamentales a efectos del diseño de modelos de prevención de delitos y sistemas de cumplimiento. ${ }^{139}$ La mayoría de los sistemas de imputación se basan en la comisión de delitos por parte de los administradores, directores y propietarios de la organización, para quienes los principios de gobernanza poseen capital relevancia. Así, si los directivos y administradores de las organizaciones no son capaces de organizarse adecuadamente, ningún modelo de prevención será eficaz. Es más: "No hay, pues, una efectiva compliance sin un sistema eficaz de gobierno corporativo". ${ }^{140}$

Estas ideas pueden ser sintetizadas de la siguiente forma: los principios de buen gobierno corporativo no solamente están en la base de los sistemas de responsabilidad, sino que asumen un carácter vinculante en materia de delitos que no contemplan deberes específicos, pues establecen la forma de dirigir y supervisar una organización. Son estas las verdaderas normas de comportamiento extrapenal que identificábamos en los capítulos anteriores, ${ }^{141}$ que constituyen el fundamento del artículo $3^{\circ}$ inciso $1^{\circ}$ parte final de la LRPPJ, y cuyo incumplimiento debe acreditarse para irrogar la responsabilidad del colectivo. ${ }^{142}$

\section{Conclusiones}

La LRPPJ exhibe en su art. $3^{\circ}$ un modelo de responsabilidad penal de las personas jurídicas, que recoge el "defecto de organización" como una categoría de imputación penal. Este requiere el incumplimiento de deberes de dirección y supervisión por parte de la persona jurídica, para justificar la aplicación de una pena en su contra. Por lo tanto, el contenido de los deberes de autorregulación y su alcance en la determinación de la responsabilidad,

\footnotetext{
136 OCDE (1999), p. 7

${ }^{137}$ HIRTH (2013), p. 28

${ }^{138}$ HIRTH (2013), p. 29.

${ }^{139}$ NIETO (2013), p. 24.

140 NIETO (2009), pp. 82 y s.

141 Véase acápite 1.3.

142 Así, por ejemplo, si se conoce la comisión de un delito de cohecho activo por parte de un miembro del directorio de una sociedad anónima, deberá observarse, si se ha cumplido con la normativa de gobiernos corporativos contemplada en la Ley $\mathrm{N}^{\circ}$ 18.046. En ese sentido, la fiscalía deberá abocarse a acreditar un desgobierno corporativo en la organización, por ejemplo, la falta de reportes a la Superintendencia o defectos en la designación de auditores externos, que comporten una infracción de sus deberes de dirección y supervisión, vinculados con el delito cometido en la especie.
} 
resultan fundamentales para la resolución de casos en que se pretenda atribuir una pena a una persona jurídica. Su adecuada comprensión requiere partir de las siguientes premisas.

El primer presupuesto a considerar es que, si bien el modelo de compliance contemplado en el art. $4^{\circ}$ tiene una evidente relación con los "deberes de dirección y supervisión" consagrados en el art. $3^{\circ}$ in. $1^{\circ}$ in fine de la LRPPJ, representa solo una forma de cumplirlos y no se identifica totalmente con ellos. En segundo lugar, este requisito de imputación cristaliza una serie de deberes y normas de conducta extrapenales que pesan sobre la organización, y que tienen por objeto mantener una cultura de legalidad y de respeto por la normativa vigente. Su contenido en concreto dice relación con las distintas obligaciones regulatorias, así como de supervisión y control pertenecientes al derecho civil y/o mercantil, que imponen deberes de organización, supervigilancia y control internos en organizaciones por los hechos de directivos, dependientes y subordinados. En tercer lugar, este requisito penal no es autosuficiente, y se apoya en normativa extrapenal que complementa su contenido.

En concordancia con lo anterior, las normas extrapenales poseen dos vertientes aplicación en la determinación de la responsabilidad penal de las personas jurídicas. Por una parte, complementan el contenido de los modelos de compliance consagrados en el art. $4^{\circ}$ de la LRPPJ, particularmente a través de estándares y reglas de control de riesgos delictivos organizacionales. Por otra, fundamentan los deberes de dirección y supervisión consagrados en el art. $3^{\circ}$ in. $1^{\circ}$ in fine de la LRPPJ. Estos últimos adquieren una relevancia fundamental para la imputación penal, en tanto la organización no haya implementado un modelo de compliance propiamente tal.

En dichos casos, el juzgador deberá evaluar, en primer lugar, si la persona jurídica ha respetado la normativa sectorial y regulatoria aplicable, cumpliendo con ella e implementando medidas de control internas específicas conforme a la actividad que realiza. Todas estas medidas deben ser consideradas, según sean ejecutadas para disminuir la probabilidad de comisión de delitos en las áreas en las que la organización desarrolla sus actividades. A contrario sensu, si se trata de un delito común, allende materias propias de regulación, deberán revisarse el cumplimiento de deberes generales aplicables a la persona jurídica imputada, relacionados con la vigilancia interna y control de los integrantes de la organización, así como las obligaciones de gobierno corporativo aplicables a la forma jurídica específica que se trate.

Finalmente, es necesario afirmar que la determinación del contenido específico de estas reglas de dirección y supervisión de organizaciones es esencialmente casuista. Ello, pues la dirección y supervisión de organizaciones depende de factores tales como su forma jurídica, giro, campo de actividades, zonas geográficas de actividades y otros factores adicionales. En tal sentido, su concretización debe realizarse por la doctrina y la jurisprudencia caso a caso, asumiendo como presupuesto fundamental la diversidad de los tipos de organización que se pretenda autorregular, para permitir su adecuada implementación por las organizaciones. 


\section{Polit. Crim. Vol. 15, No 30 (Diciembre 2020), Art. 7, pp. 694-728 \\ [http://politcrim.com/wp-content/uploads/2020/12/Vol15N30A7.pdf]}

\section{Bibliografía citada}

ALBERTZ ARÉVALO, Pablo (2019): "Identificación, análisis, evaluación y control de riesgos de corrupción en la empresa", en: ARTAZA VARELA, Osvaldo (Dir.), Compliance penal: Sistemas de prevención de la corrupción (Santiago, DER Ediciones), pp. 115-202.

ARTAZA VARELA, Osvaldo (2019): "Propuesta relativa a los criterios de atribución de responsabilidad penal a personas jurídicas en Chile", en: ARTAZA VARELA, Osvaldo (Dir.), Compliance penal: Sistemas de prevención de la corrupción (Santiago, DER Ediciones), pp. 37-62.

ARTAZA VARELA, Osvaldo (2013a): La empresa como sujeto de imputación de responsabilidad penal. Fundamentos y límites (Madrid, Marcial Pons).

ARTAZA VARELA, Osvaldo (2013b): "Sistemas de prevención de delitos o programas de cumplimiento. Breve descripción de las reglas técnicas de gestión del riesgo empresarial y su utilidad en sede jurídico penal", en: Política Criminal, (Vol. 8, $\left.\mathrm{N}^{\circ} 16\right)$, pp. 544-573.

BACIGALUPO ZAPATER, Enrique (1999): Derecho penal. Parte general, $2^{\mathrm{a}}$ ed. (Buenos Aires, Hammurabi).

BAFIN (2018): “Auslegungs und Anwendungshinweise zum Geldwäschegesetz”. Disponible en: https://bit.ly/2sCGqlU [fecha de visita: 1.12.2020]

BALMACEDA HOYOS, Gustavo; GUERRA ESPINOSA, Rodrigo; JUPPET EWING, María (2019): Compliance. Visión general desde una perspectiva penal y comercial (Santiago, Legal Publishing Chile).

BEDECARRATZ SCHOLZ, Francisco Javier (2018): "La indeterminación del criminal compliance y el principio de legalidad", en: Política Criminal (Vol. 13, № 25), pp. 208-232.

BEDECARRATZ SCHOLZ, Francisco Javier (2016): Rechtsvergleichende Studien zur Strafbarkeit juristischer Personen. Eine Untersuchung ihrer Strafzurechnungsmerkmale in den Rechtsordnungen von Chile, Deutschland, England, Frankreich, Spanien und den Vereinigten Staaten (Baden-Baden, Nomos Verlagsgesellschaft).

BINDING, Karl (1965): Die Normen und ihre Übertretung (Aalen, Scientia Verag).

BINDING, Karl (1885): Handbuch des Strafrechts (Leipzig, Duncker \& Humblot).

BOCK, Dennis (2013): “Compliance y deberes de vigilancia en la empresa”, en: KUHLEN, Lothar, MONTIEL, Juan Pablo, ORTIZ DE URBINA GIMENO, Íñigo (Eds.), Compliance y teoría del Derecho penal (Madrid, Marcial Pons), pp. 107-121.

BOFILL GENZSCH, Jorge (2011): "Estructuras de imputación y prevención de delitos al interior de la persona jurídica", en: WILENMANN VON BERNATH, Javier (Coord.), Gobiernos corporativos. Aspectos esenciales de las reformas a su regulación (Santiago, Legal Publishing Chile), pp. 175-195.

BÖSE, Martin (2014): "Strafbarkeit juristischer Personen - Selbstverständlichkeit oder Paradigmenwechsel im Strafrecht", en: Zeitschrift für die gesamte Strafrechtswissenschaft ( $\left.\mathrm{N}^{\circ} 126\right)$, pp. 132-165.

BRAITHWAITE, John (1982): "Enforced Self-Regulation: A New Strategy for Corporate Crime Control”, en: Michigan Law Review (Vol. 80, N 7), pp. 1466-1507. 
CARBONELL MATEU, Juan Carlos (2011): "Die strafrechtliche Verantwortlichkeit juristischer Personen: Überlegungen zur „Dogmatik“ und zum System der Reform des spanischen Strafgesetzbuchs 2010", en: Zeitschrift für die gesamte Strafrechtswissenschaft $\left(\mathrm{N}^{\circ} 123\right)$, pp. 332-346.

COLLADO GONZÁLEZ, Rafael (2013): Empresas Criminales (Santiago, Legal Publishing Chile).

DE LA CUESTA ARZAMENDI, José Luis (2012): "Responsabilidad penal de las personas jurídicas en el Derecho español", en: Electronic Review of the International Association of Penal Law (A-01), pp. 1-28.

DEL ROSAL BLASCO, Bernardo (2011): “La delimitación típica de los llamados hechos de conexión en el nuevo artículo 31 bis, $\mathrm{n}^{\mathrm{o}}$ 1, del Código Penal”, en: Cuadernos de Política Criminal ( $\left.\mathrm{N}^{\circ} 103\right)$, pp. 41-94.

DÓPICO GÓMEZ-ALLER, Jacobo (2014): "Posición de garante del compliance officer por una infracción del "deber de control": Una aproximación tópica”, en: MIR PUIG, Santiago; CORCOY BIDASOLO, Mirentxu; GÓMEZ MARTÍN, Víctor (Dirs.), Responsabilidad de la Empresa y Compliance (Buenos Aires, Edisofer), pp. 337-363.

ENGELHART, Marc (2012): Sanktionierung von Unternehmen und Compliance, $2^{\mathrm{a}}$ ed. actualizada (Berlin, Duncker \& Humblot).

FARALDO CABANA, Patricia (2019): "Medidas para contener la culpabilidad en los delitos imputables a las empresas en España", en: Revista da Faculdade de Direito da FMP (Vol. 14, $\mathrm{N}^{\circ}$ 1), pp. 48-75.

FATEH-MOGHADAM, Bijan (2011): “Operativer Funktionalismus in der Strafrechtsvergleichung", en: BECK, Susanne, BURCHARD, Christoph, FATEHMOGHADAM, Bijan, Strafrechtsvergleichung als Problem und Lösung, (BadenBaden, Nomos Verlagsgesellschaft), pp. 43-63.

FEIJOO SÁNCHEZ, Bernardo (2016): El delito corporativo en el Código Penal español, $2^{\circ}$ ed. (Cizur Menor, Civitas).

FERNÁNDEZ TERUELO, Javier Gustavo (2019): “Responsabilidad penal de las personas jurídicas. El contenido de las obligaciones de supervisión, organización, vigilancia y control referidas en el art. 31 bis 1. b) del Código Penal español”, en: Revista Electrónica de Ciencia Penal y Criminología ( $\left.\mathrm{N}^{\circ} 21-03\right)$, pp. 1-25.

FISCAL NACIONAL DEL MINISTERIO PÚBLICO (2010): Oficio FN N 440/2010 del 23 de agosto de 2010. Disponible en: https://bit.ly/30S8Gh4 [fecha de visita 1.12.2020].

FREUND, Georg (2019): “Determinación legal de la punibilidad en los delitos imprudentes”, en: Revista de Estudios de la Justicia ( $\left.\mathrm{N}^{\circ} 31\right)$, pp. 1-15.

FREUND, Georg (2015): "Verfassungswidrige Dopingstrafbarkeit nach $§ 95$ Abs. 1 Nr. $2 \mathrm{a}$ AMG - Ein Beitrag zum Gesetzlichkeitsgrundsatz (Art. 103 Abs. 2 GG)", en: BANNENBERG, Britta; BRETTEL, Hauke; FREUND, Georg; MEIER, BerndDieter; REMSCHMIDT, Helmut; SAFFERLING, Christoph (eds.), Über allem: Menschlichkeit - Festschrift für Dieter Rössner (Baden-Baden, Nomos Verlagsgesellschaft), pp. 579-598.

GARCÍA CAVERO, Percy (2014): Criminal Compliance (Lima, Palestra Editores S.A.C.).

GARCÍA CAVERO, Percy (2012): "Esbozo de un modelo de atribución de responsabilidad penal de las personas jurídicas", en: Revista de Estudios de la Justicia ( $\left.\mathrm{N}^{\circ} 16\right)$, pp. $55-74$. 
GÓMEZ-JARA DÍEZ, Carlos (2005): La culpabilidad penal de la empresa (Madrid, Marcial Pons).

HERNÁNDEZ BASUALTO, Héctor (2013): “Die Betriebsbezogenheit der Garantenstellung von Leitungspersonen im Unternehmen”, en: FREUND, Georg; MURMANN, Uwe; BLOY, René; PERRON, Walter (Eds.), Grundlagen und Dogmatik des gesamten Strafrechtssystems. Festschrift für Wolfgang Frisch zum 70. Geburtstag (Berlin, Duncker \& Humblot), pp. 333-348.

HERNÁNDEZ BASUALTO, Héctor (2012): "Desafíos de la ley de responsabilidad penal de las personas jurídicas", en: Revista de Estudios de la Justicia ( $\left.\mathrm{N}^{\circ} 16\right)$, pp. 75-98.

HERNÁNDEZ BASUALTO, Héctor (2010): "La introducción de la responsabilidad penal de las personas jurídicas en Chile”, en: Política Criminal (Vol. 5, N 9), pp. 207-236.

HIRTH, Philipp (2013): Corporate Governance in Non-Profit-Organisationen. StakeholderManagement zwischen finanziellen Interessen und Glaubwürdigkeit, (Wiesbaden, Springer VS).

HRUSCHKA, Joachim (1994): "Reglas de comportamiento y reglas de imputación" (Traducción de Francisco Baldó Lavilla), en: Anuario de derecho penal y ciencias penales (Tomo 47, Fasc/Mes 3), pp. 343-356.

KALIN, Christian (2014): Verhaltensnorm und Kollisionsrecht (Tübingen, Mohr Siebeck).

LEO-CASTELA, Juan Ignacio; RODRÍGUEZ-LÓPEZ, Fernando; SÁNCHEZ MACÍAS, José Ignacio (2019): "Evolución de la responsabilidad social y legal corporativa: hacia un índice de compliance en la OCDE”, en: RODRÍGUEZ-GARCÍA, Nicolás; CARRIZO, Adán; RODRÍGUEZ-LÓPEZ, Fernando (eds.): Corrupción: compliance, represión y recuperación de activos (Valencia, Tirant lo Blanch), pp. 405-425.

GUTIÉRREZ PÉREZ, Elena (2015): "Los compliance programs como eximente o atenuante de la responsabilidad penal de las personas jurídicas. La "eficacia e idoneidad" como principios rectores tras la reforma de 2015", en: Revista General de Derecho Penal ( $\left.\mathrm{N}^{\circ} 24\right)$, pp. 1-24.

MAÑALICH RAFFO, Juan Pablo (2010): "Norma e imputación como categorías del hecho punible", en: Revista de Estudios de la Justicia ( $\left.\mathrm{N}^{\circ} 12\right)$, pp. 169-190.

MATUS ACUÑA, Jean Pierre (2017): "Sobre el valor de las certificaciones de adopción e implementación de modelos de prevención de delitos frente a la responsabilidad penal de las personas jurídicas", en: Revista de Derecho, Empresa y Sociedad ( No 11), pp. 38-43.

MICHAELS, Ralf (2008): “The Functional Method of Comparative Law”, en: REIMANN, Mathias; ZIMMERMANN, Reinhard (Eds.), The Oxford Handbook of Comparative Law (Oxford, Oxford University Press), pp. 339-382.

MITSCH, Wolfgang (2018): "Einleitung", en: MITSCH, Wolfgang (ed.), Karlsruher Kommentar zum Gesetz über Ordnungswidrigkeiten, $5^{\mathrm{a}}$ ed. actualizada (München, C.H. Beck), pp. 1-54.

NAVAS MONDACA, Iván; JAAR LABARCA, Antonia (2018): “La responsabilidad penal de las personas jurídicas en la jurisprudencia chilena”, en: Política Criminal (Vol. 13, $\left.\mathrm{N}^{\mathrm{0}} 26\right)$, pp. 1027-1054.

NEIRA PENA, Ana María (2016): "La efectividad de los criminal compliance programs como objeto de prueba en el proceso penal”, en: Política Criminal, (Vol. 11, N²2), pp. 467-520. 
NIETO MARTÍN, Adán (2013): "Problemas fundamentales del cumplimiento normativo en el Derecho penal", en: KUHLEN, Lothar, MONTIEL, Juan Pablo, ORTÍZ DE URBINA GIMENO, Íñigo (Eds.), Compliance y teoría del Derecho Penal (Madrid, Marcial Pons), pp. 21-50.

NIETO MARTÍN, Adán (2012): "Cosmetic Use and Lack of Precision in Compliance Programs: Any Solution?”, en: Eucrim (2012/3), pp. 124-127.

NIETO MARTÍN, Adán (2008a): La Responsabilidad Penal de las Personas Jurídicas: un Modelo Legislativo (Madrid, Iustel).

NIETO MARTÍN, Adán (2008b): "Responsabilidad social, gobierno corporativo y autorregulación: Sus influencias en el derecho penal de la empresa", en: Política Criminal (Vol. 3, $\mathrm{N}^{\circ}$ 5), pp. 1-18.

ORGANIZACIÓN PARA LA COOPERACIÓN Y DESARROLLO ECONÓMICO (1999): OECD Principles of Corporate Governance (Paris, OECD Publishing). Disponible en: https://bit.ly/2OGuBnB [fecha de visita 1.12.2020].

PIÑA ROCHEFORT, Juan Ignacio (2012): Modelos de Prevención de Delitos en la Empresa (Santiago, Legal Publishing Chile).

POLITOFF LIFSCHITZ, Sergio, MATUS ACUÑA, Jean Pierre, RAMÍREZ GUZMÁN, María Cecilia (2003): Lecciones de derecho penal chileno. Parte general, $2^{\mathrm{a}}$ ed. (Santiago, Editorial Jurídica de Chile).

RENZIKOWSKY, Joachim (2005): “Normentheorie und Strafrechtsdogmatik”, en: ALEXY, Robert (Ed.), Juristische Grundlagenforschung (Wiesbaden, Franz Steiner Verlag), pp. 115-137.

RIBERA NEUMANN, Teodoro (2011): "Requisitos Constitucionales para Limitar los Derechos Fundamentales", en: Estudios sobre Justicia Constitucional: Libro Homenaje a la Profesora Luz Bulnes Aldunate (Santiago, Editorial Jurídica de Chile), pp. 231-268.

RIBERA NEUMANN, Teodoro (2007): "La protección constitucional de la empresa: La individualidad determinada y la teoría del levantamiento del velo", en: FERMANDOIS VÖHRINGER, Arturo (Ed.), Sentencias destacadas 2006 (Santiago, Instituto Libertad y Desarrollo), pp. 275-298.

ROBLES PLANAS, Ricardo (2012): "Strafe und juristische Person. Eine Kritik des Art. 31bis des spanischen Strafgesetzbuches", en: Zeitschrift für Internationale Strafrechtsdogmatik, (No 7), pp. 347-360.

ROGALL, Klaus (2018a): " $\$ 30$ Geldbuße gegen juristische Personen und Personenvereinigungen", en: MITSCH, Wolfgang (ed.), Karlsruher Kommentar zum Gesetz über Ordnungswidrigkeiten, $5^{\text {a }}$ ed. actualizada (München, C.H. Beck), pp. 517-610.

ROGALL, Klaus (2018b): “\$130 Verletzung der Aufsichtspflicht in Betrieben und Unternehmen", en: MITSCH, Wolfgang (ed.), Karlsruher Kommentar zum Gesetz über Ordnungswidrigkeiten, $5^{\text {a }}$ ed. actualizada (München, C.H. Beck), pp. 18121857.

ROJAS MORÁN, Luciano (2019): "Responsabilidad penal de las personas jurídicas. Consideraciones generales", en: ARTAZA VARELA, Osvaldo (Dir.), Compliance penal: Sistemas de prevención de la corrupción (Santiago, DER Ediciones), pp. 7-34. 


\section{Polit. Crim. Vol. 15, No 30 (Diciembre 2020), Art. 7, pp. 694-728 \\ [http://politcrim.com/wp-content/uploads/2020/12/Vol15N30A7.pdf]}

ROTH, Barbara (2019): “Der Geldwäschebeauftragte: Rollen- und Aufgabenprofil nach $§ 7$ GwG”, en: GEHRA, Bernhard, GITTFRIED, Norbert; LIENKE, Georg, Prävention von Geldwäsche und Terrorismusfinanzierung (Heidelberg, C.F. Müller).

SILVA SÁNCHEZ, Jesús María (2018): Fundamentos del Derecho penal de la Empresa, $2^{\text {a }}$ ed. ampliada y actualizada (Buenos Aires, Edisofer).

TIEDEMANN, Klaus (1988): “Die „Bebußung“ von Unternehmen nach dem 2. Gesetz zur Bekämpfung der Wirtschaftskriminalität”, en: Neue Juristische Wochenschrift (cuaderno $\left.\mathrm{N}^{\circ} 19\right)$, pp. 1169-1174.

VAN WEEZEL DE LA CRUZ, Alex (2010): “Contra la responsabilidad penal de las personas jurídicas”, en: Política Criminal (Vol. 5, N 9), pp. 114-142.

VARELA, Lorena (2016): Dolo y error. Una propuesta para una imputación auténticamente subjetiva (Madrid, José María Bosch Editor).

ZITELMANN, Ernst (1897): Internationales Privatrecht (Leipzig, Verlag von Duncker \& Humblot), tomo I. Disponible en: https://bit.ly/30a9YU1 [fecha de visita: 1.12.2020].

ZWEIGERT, Konrad; KÖTZ, Hein (1996): Einführung in die Rechtsvergleichung, $3^{\circ}$ ed. (Tübingen, Mohr Siebeck).

\section{Jurisprudencia citada}

$8^{\circ}$ Juzgado de Garantía de Santiago, causa RIT N 4799-2012, RUC N $1200084351-0,2$ de junio de 2016.

$7^{\circ}$ Juzgado de Garantía de Santiago, RIT No 11862-2014, RUC N ${ }^{\circ}$ 1400129785-7, 19 de agosto de 2015.

Juzgado de Garantía de Talca, causa RIT No 9211-2012, RUC No 1201092968-5, 12 de agosto de 2013.

Sentencia del Tribunal Supremo alemán del 2 de diciembre de 1991, BGHSt 38, 138. 